\title{
Major components of atmospheric organic aerosol in southern California as determined by hourly measurements of source marker compounds
}

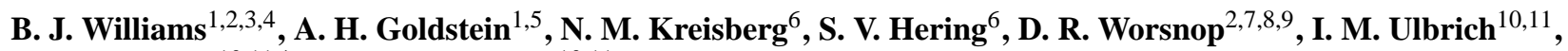 \\ K. S. Docherty ${ }^{10,11, *}$, and J. L. Jimenez ${ }^{10,11}$ \\ ${ }^{1}$ Dept. of Environmental Science, Policy, \& Management, University of California, 147 Mulford Hall, Berkeley, CA, USA \\ ${ }^{2}$ Center for Aerosol and Cloud Chemistry, Aerodyne Research Inc., 45 Manning Rd., Billerica, MA, USA \\ ${ }^{3}$ Dept. of Mechanical Engineering, University of Minnesota, 271 Mechanical Engineering, 111 Church Street S.E., \\ Minneapolis, MN, USA \\ ${ }^{4}$ Dept. of Energy, Environmental, and Chemical Engineering, Washington University in St. Louis, 3026 Brauer Hall, St. \\ Louis, MO, USA \\ ${ }^{5}$ Dept. of Civil and Environmental Engineering, University of California, 147 Mulford Hall, Berkeley, CA, USA \\ ${ }^{6}$ Aerosol Dynamics Inc., 935 Grayson St., Berkeley, CA, USA \\ ${ }^{7}$ Dept. of Physics, University of Kuopio, Kuopio, Finland \\ ${ }^{8}$ Finnish Meteorological Institute, Helsinki, Finland \\ ${ }^{9}$ Dept. of Physics, University of Helsinki, Helsinki, Finland \\ ${ }^{10}$ Dept. of Chemistry and Biochemistry, University of Colorado, Boulder, CO, USA \\ ${ }^{11}$ Cooperative Institute for Research in the Environmental Sciences, Boulder, CO, USA \\ " now at: Alion Science and Technology, EPA Office of Research and Development, Research Triangle Park, NC, USA
}

Received: 26 February 2010 - Published in Atmos. Chem. Phys. Discuss.: 9 March 2010

Revised: 15 November 2010 - Accepted: 17 November 2010 - Published: 7 December 2010

\begin{abstract}
We report the first hourly in-situ measurements of speciated organic aerosol (OA) composition in an urban environment. Field measurements were made in southern California at the University of California-Riverside during the 2005 Study of Organic Aerosol at Riverside (SOAR), which included two separate measurement periods: a summer study (15 July-15 August) and a fall study (31 October-28 November). Hourly measurements of over 300 semivolatile and nonvolatile organic compounds were made using the thermal desorption aerosol gas chromatograph (TAG). Positive matrix factorization (PMF) was performed on a subset of these compounds to identify major components contributing to submicron (i.e., $\mathrm{PM}_{1}$ ) OA at the site, as measured by an aerosol mass spectrometer (AMS). PMF analysis was performed on an 11-day focus period in each season, representing average seasonal conditions during the summer and a period of urban influence during the fall. As a result of
\end{abstract}

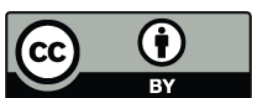

Correspondence to: B. J. Williams (brentw@seas.wustl.edu) this analysis, we identify multiple types of primary and secondary OA (POA and SOA). Secondary sources contribute substantially to fine OA mass at Riverside, which commonly receives regional air masses that pass through metropolitan Los Angeles during the summer. Four individual summertime SOA components are defined, and when combined, they are estimated to contribute an average $88 \%$ of the total fine OA mass during summer afternoons according to PMF results. These sources appear to be mostly from the oxidation of anthropogenic precursor gases, with one SOA component having contributions from oxygenated biogenics. During the fall, three out of four aerosol components that contain SOA are inseparable from covarying primary emissions, and therefore we cannot estimate the fraction of total OA that is secondary in nature during the fall study. Identified primary OA components are attributed to vehicle emissions, food cooking, primary biogenics, and biomass burning aerosol. While a distinction between local and regional vehicle emissions is made, a combination of these two factors accounted for approximately $11 \%$ of observed submicron OA during both sampling periods. Food cooking operations contributed

Published by Copernicus Publications on behalf of the European Geosciences Union. 
$\sim 10 \%$ of submicron OA mass during the summer, but was not separable from SOA during the fall due to high covariance of sources. Biomass burning aerosol contributed a larger fraction of fine OA mass during the fall $(\sim 11 \%)$ than compared to summer $(\sim 7 \%)$. Primary biogenic aerosol was also identified during the summer, contributing $\sim 1 \%$ of the OA, but not during the fall. While the contribution of both local and regional primary vehicle OA accounts for only $\sim 11 \%$ of total OA during both seasons, gas-phase vehicle emissions likely create a substantial fraction of the observed SOA as a result of atmospheric processing.

\section{Introduction}

The Study of Organic Aerosol at Riverside (SOAR) was conducted to gain a better understanding of the sources and processes responsible for the formation of organic aerosol (OA) (Docherty and Jimenez, 2005). Sampling during SOAR was conducted during the summer (SOAR-1) and fall (SOAR-2) of 2005 on the campus of the University of California-Riverside. All analyses performed throughout this manuscript use data taken during defined seasonal focus periods of 29 July- 8 August (summer) and 4 November14 November (fall). Riverside is located within the South Coast Air Basin which is currently out of compliance with state and federal air quality standards for atmospheric particles with diameters below $2.5 \mu \mathrm{m}$ (EPA, 2009; CARB, 2009), which have detrimental affects on human health (Dockery et al., 1993; Schwartz et al., 1996; Jang et al., 2006; Pope et al., 2009) and cause changes to Earth's radiation balance (IPCC, 2007) and hydrological cycle (Kanakidou et al., 2005; Ramanathan et al., 2001). OA is a major constituent of airborne particles globally, comprising $20-90 \%$ of fine particle mass in many regions (Murphy et al., 2006; Zhang et al., 2007) and is either directly emitted into the atmosphere in the particlephase ("primary" OA, POA) or formed from gas-to-particle conversion processes ("secondary" OA, SOA). The chemical composition of OA is complex with hundreds of organic compounds having been identified through chromatography and mass spectrometry techniques, even though the majority of the OA mass is typically not analyzable by direct speciation techniques. This complexity presents a challenge to the full characterization of organic particles and their sources and processing.

A wide range of aerosol instrumentation was used to gather complementary information on the physical and chemical properties of aerosols arriving at the SOAR field site, including the thermal desorption aerosol gas chromatograph (TAG) which provides information regarding the molecular composition of OA (Williams et al., 2006) and will be the main focus of this paper. Additionally, an aerosol mass spectrometer (AMS) is used to obtain total OA mass concentrations. Docherty et al. (2008) have compared the re- sults of five methods to estimate the SOA/OA fraction and diurnal cycle during SOAR-1, and all methods consistently pointed towards the dominance of SOA with a contribution of about $70-95 \%$ during the afternoons and $45-70 \%$ during the early morning. These results contrast strongly with previous studies carried out in Riverside and nearby locations, as well as modeling studies, which have consistently reported SOA/OA $<50 \%$ during the summer (with the exception of severe photochemical episodes with $\mathrm{O}_{3}>200 \mathrm{ppb}$ which did not apply during SOAR-1) (e.g., Appel et al., 1979; Pandis et al., 1992; Turpin and Huntzicker, 1995). This discrepancy is likely due to problems in the methods applied to obtain previous estimates (EC tracer method and SOA modeling in particular) and potentially changes in the fraction of SOA in the South Coast Air Basin due to a larger decrease in POA emissions compared to SOA precursor emissions, as discussed by Docherty et al. (2008). A combination of TAG and AMS measurements helps assemble a more complete picture of how OA is formed within the South Coast Air Basin and the transformations it undergoes in the atmosphere. To help understand how OA is formed and modified, the various components of OA must first be identified based on distinct physical and chemical characteristics. The focus of this paper is to determine major components of ambient OA in Riverside, CA using information provided by several novel measurement techniques. This information is then used to infer major sources of OA that likely contribute to the impact of aerosols on human health effects, changes in the hydrological cycle, and changes in the global radiation balance.

\section{Methods}

\subsection{Field site}

The SOAR field site was located in Riverside, CA $\left(33^{\circ} 58^{\prime} 18^{\prime \prime} \mathrm{N}, 117^{\circ} 19^{\prime} 17^{\prime \prime} \mathrm{W}\right)$ on the University of California-Riverside campus, which is approximately $80 \mathrm{~km}$ to the east-southeast of downtown Los Angeles, $\mathrm{CA}$, and $0.6 \mathrm{~km}$ east of interstate 215 . Interstate highway 215 carries an annual average of 173000 vehicles per day through Riverside, CA as reported in 2002 (Caltrans, 2007) representing a local source of primary emissions.

Riverside is contained within the eastern edge of the greater South Coast Air Basin. Airborne pollutants are easily trapped within the basin by the surrounding Santa Susanna, Santa Monica, San Gabriel, and San Bernardino Mountains to the north, the Santa Ana Mountains to the south, and the San Jacinto Mountains to the east. The population of the entire Los Angeles metropolitan area (i.e., Los Angeles County, Orange County, Ventura County, San Bernardino County, and Riverside County) in 2006 was estimated at 17.8 million people (US Census Bureau, 2008). The South Coast Air Basin is home to many industries and has high land, 


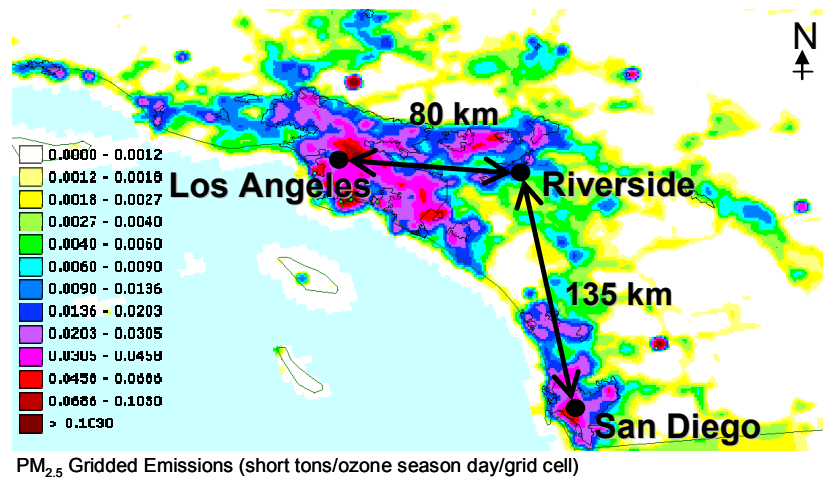

Fig. 1. View of the ground-based field site at Riverside, CA $\left(33^{\circ} 58^{\prime} 18^{\prime \prime} \mathrm{N}, 117^{\circ} 19^{\prime} 17^{\prime \prime} \mathrm{W}\right)$. Shown are anthropogenic $\mathrm{PM}_{2.5^{-}}$ PRI emissions in short tons/ozone season day/grid cell, plotted on a 4-km Lambert-Conformal grid. This emission map was created using the NOAA-NESDIS/OAR Emission Inventory Mapviewer found at: (http://map.ngdc.noaa.gov/website/al/emissions/viewer. htm), maintained by Gregory Frost, NOAA.

sea, and air traffic, and therefore serves as a major aerosol emission region (Fig. 1). The basin is large enough to retain much of the primary aerosols throughout the day, allowing enough time for those particles to undergo photochemical reactions in the atmosphere, as well as photooxidize primary gas-phase emissions, creating lower volatility reaction products that partition into the particle phase forming secondary aerosol (inorganic and organic).

The typical daytime wind direction is from west to east (Fig. 2), carrying pollutant emissions from Los Angeles to Riverside, and creating a significant amount of regional secondary aerosol in transit. Average nighttime winds typically came from the south or southeast at low wind speeds (Fig. 2). Located directly to the southeast of the study site is a large botanical garden, and to the south and southwest is a wide range of test crop groves, potentially resulting in biogenic contributions to the measurements reported here, which are probably enhanced at night due to reduced dilution. Exceptions to this typical diurnal wind pattern were observed during the fall, when high pressure systems arrived from the north, forcing dry desert air to move from the east back to the west. These wind patterns are known as the "Santa Ana" winds.

A wide range of meteorological, radiation, trace gas and aerosol measurements were made during the SOAR campaign, but only instrumentation used to generate conclusions contained within this paper will be described here. The majority of data presented here is hourly in-situ speciated organic aerosol composition measured using the TAG system, described by Williams et al. (2006, 2007). Other relevant instrumentation included an Aerodyne high-resolution timeof-flight aerosol mass spectrometer (HR-ToF-AMS, hereinafter "AMS" for short) which measures non-refractory

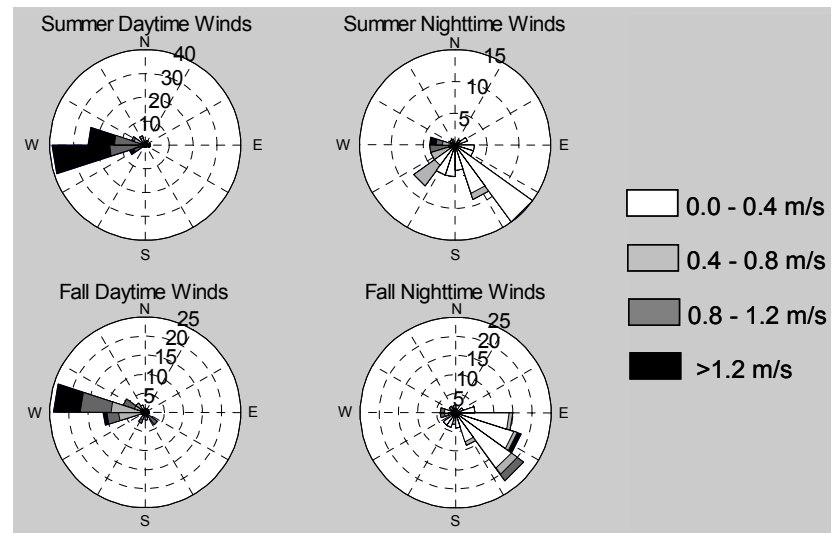

Fig. 2. Hourly average daytime and nighttime winds, measured at TAG inlet height (i.e., $7 \mathrm{~m}$ ), for SOAR focus periods, separated by summer (29 July-8 August) and fall (4 November-14 November) 2005. Concentric rings represent frequency of observations.

$\mathrm{PM}_{1}$ aerosol components (NR-PM ${ }_{1}$ ) (DeCarlo et al., 2006; Canagaratna et al., 2007; Docherty et al., 2008; Cubison et al., 2008), an in-situ gas-phase preconcentration GC-MSDFID for volatile organic compound (VOC) and oxygenated volatile organic compound (OVOC) concentrations (Millet et al., 2006; Gentner et al., 2009), and an aerosol time-offlight mass spectrometer (ATOFMS), which produces detailed mass spectra of individual particles, detecting fragments from organic carbon, elemental carbon, sulfate, nitrate, metals, chloride, ammonium, and additional species (Noble and Prather, 1996; Shields et al., 2008). Other supporting measurements include: carbon monoxide (CO) measured by nondispersive infrared absorption (TEI, model 48C), $\mathrm{CO}_{2}$ and $\mathrm{H}_{2} \mathrm{O}$ by infrared absorption (Li-Cor Inc., model LI-6262), ozone measured using a UV photometric $\mathrm{O}_{3}$ analyzer (Dasibi Inc., model 1008-RS), total particulate organic carbon (OC) and total elemental carbon (EC) measured using an OCEC monitor (Sunset Labs) (Snyder et al., 2007), photosynthetically active radiation (PAR) measured with a quantum sensor (Li-Cor Inc., model LI-190SZ) which will be referred to as "visible light" throughout, wind speed and direction by propeller wind monitor (R. M. Young Co.), and temperature and relative humidity were monitored on an RH\&T probe (Campbell Scientific Inc., model HMP45C). A list of abbreviations used in this paper is provided in Table 1.

\subsection{TAG instrument calibration}

Details on TAG operation are provided by Williams et al. (2006). Briefly described, particles are collected by humidification followed by inertial impaction and subsequent thermal desorption into a gas chromatograph - mass spectrometer. A separation between gas and particle phase collection is determined through periodic filtration of the particle phase. Details on TAG calibration as performed during 
Table 1. List of Abbreviations used in this Manuscript.

\begin{tabular}{|c|c|c|c|}
\hline AMS & Aerosol Mass Spectrometer & & TAG-PMF Components: \\
\hline ATOFMS & Aerosol Time-Of-Flight Mass Spectrometer & & \\
\hline BAM & Beta Attenuation Monitor & SOA1 & Secondary Organic Aerosol (SOA) type 1 \\
\hline $\mathrm{BC}$ & Black Carbon & SOA2 & SOA type 2 \\
\hline CMB & Chemical Mass Balance & SOA3 & SOA type 3 \\
\hline CTD & Collection and Thermal Desorption & $\mathrm{SOA} 4+\mathrm{SV}$ & SOA type $4+$ Semivolatiles \\
\hline$C_{\text {wax }}$ & Excess Odd Carbon from C25-C31 Alkanes & RPA & Regional Primary Anthropogenic \\
\hline EC & Elemental Carbon & LV & Local Vehicle \\
\hline FID & Flame Ionization Detector & $\mathrm{FC}$ & Food Cooking \\
\hline GC & Gas Chromatography & BB & Biomass Burning \\
\hline HR-ToF-AMS & High Resolution Time-of-Flight AMS & Bio & Biogenic (Primary) \\
\hline IP & Instrument Precision & $\mathrm{SOA}+\mathrm{FC} 1$ & SOA + Food Cooking type 1 \\
\hline MSD & Mass Selectivity Detector & $\mathrm{SOA}+\mathrm{FC} 2$ & SOA + Food Cooking type 2 \\
\hline MV & Missing Value & & \\
\hline MW & Molecular Weight & \multicolumn{2}{|r|}{ ATOFMS - Single Particle Types: } \\
\hline$m / z$ & Mass to Charge ratio & & \\
\hline nonvol-57 & Total low volatility $\mathrm{m} / \mathrm{z}, 57$ signal & AgedOC1 & Aged organics without sulfate type 1 \\
\hline $\mathrm{OA}$ & Organic Aerosol & AgedOCSO4 & Aged organics containing sulfate \\
\hline $\mathrm{OC}$ & Organic Carbon & AgedOC2 & Aged organics without sulfate type 2 \\
\hline $\mathrm{OM}$ & Organic Matter & ECOCSO4 & Organics with elemental carbon and sulfate \\
\hline OOA & Oxygenated Organic Aerosol & ECOC & Organics containing elemental carbon \\
\hline OOA/OA & Fraction of total OA that is OOA & $\mathrm{EC}$ & Elemental carbon alone \\
\hline OVOC & Oxygenated VOC & Amine & Amine-rich particles \\
\hline $\mathrm{O}_{\mathrm{x}}$ & Odd Oxygen & $\mathrm{V}$ & Vanadium-rich particles \\
\hline ox-nonvol-43 & Total low volatility $\mathrm{m} / \mathrm{z} 43$ signal (oxygenated fragment only) & Biomass & Biomass particles rich in potassium \\
\hline AgedSS & Aged sea salt particles & & \\
\hline PAH & Polycyclic Aromatic Hydrocarbon & Dust & Dust particles \\
\hline PAR & Photosynthetically Active Radiation & NH4NO3 & Ammonium nitrate-rich particles \\
\hline $\mathrm{PM}_{1}$ & Particulate Matter w/diameters $<1 \mu \mathrm{m}$ & & \\
\hline PMF & Positive Matrix Factorization & & \\
\hline POA & Primary Organic Aerosol & & \\
\hline PST & Pacific Standard Time $(=\mathrm{UTC}-8 \mathrm{~h})$ & & \\
\hline$Q$ & Minimized sum of squares from PMF analysis & & \\
\hline$Q_{\exp }$ & Expected minimized sum of squares from PMF analysis & & \\
\hline$s_{i j}$ & Uncertainty in concentration of compound $j$ at hour $i$ & & \\
\hline SOA & Secondary Organic Aerosol & & \\
\hline $\mathrm{SOA} / \mathrm{OA}$ & Fraction of total OA that is SOA & & \\
\hline SOAR & Study of Organic Aerosol at Riverside & & \\
\hline TAG & Thermal desorption Aerosol Gas Chromatograph & & \\
\hline $\mathrm{UCM}$ & Unresolved Complex Mixture & & \\
\hline VOC & Volatile Organic Compound & & \\
\hline$x_{i j}$ & Concentration of compound $j$ at hour $i$ & & \\
\hline
\end{tabular}

SOAR are reported in Kreisberg et al. (2009). A brief description is provided here. Liquid standards are manually injected with a $5 \mu \mathrm{L}$ syringe directly into the collection and thermal desorption (CTD) cell via a septum port. After injection, the standard is thermally desorbed and analyzed in an identical manner to an ambient sample.

There were 11 authentic standard mixtures analyzed during SOAR, ten of which were auxiliary standards run on an infrequent basis, and one of which was a daily-run tracking standard, which consisted of a full spectrum of compound polarity and molecular size. This tracking standard was used to determine detector response drift. For the summer (fall) field study a total of 58 (64) distinct standard injections were performed. Of these, approximately one-half were of the tracking standard and the remainder spread across the other standard sets. In total, over 200 organic compounds of varying functional groups and varying polarities were calibrated for in the 11 mixes. Each standard set was introduced at various concentrations to obtain a detector response curve.

Over the course of seasonal focus periods the average detector response drifted by approximately $-18 \%$ during the summer study and $-17 \%$ during the fall study (see Supplement, Table S1). This drift is likely due to detector drift (e.g., natural decay of the electron multiplier detector with use, voltage drifts, cleanliness of source affecting electric fields) and partially due to GC column condition. The 
MSD drift appears to vary by compound (Table S1), which is likely more a function of column condition than detector drift. The most accurate drift evaluation would be based on a compound-by-compound drift quantification. Unfortunately, the data needed to implement such an approach is not available for this study. In fact, a number of issues with the calibration method used during SOAR have been realized through the data analysis and subsequent experiments, and hence a new automated calibration system for the TAG system is under development (and was first deployed on TAG systems during the CalNex 2010 study). With the automated calibration system, we are able to achieve injections of deuterated internal standards onto every single ambient sample. This stands to be the most accurate way of determining drift, as it captures transfer effects from the ambient matrix, which are missed using an external standard.

With regard to the SOAR study discussed in this paper, it is estimated that biases from infrequent external injections will be larger than biases introduced by assuming a constant detector drift across all compounds. To avoid increasing uncertainty for PMF input data, we make the assumption that detector response drift is constant for all compounds, and apply a correction for the average detector drift across the seasonal focus periods for all compounds. A sensitivity test using zero detector drift derived the same source apportionment results as those derived using seasonal-average detector drifts (Fig. S1).

It can be envisioned that if a strong drift which has not been largely accounted for by our applied average detector drift does exist across entire classes of compounds (as would be expected for column-influenced drifts), then a separate PMF factor could arise that is purely influenced by this drift. Since we do not observe any PMF factors that would only be influenced by systematic variations in a specific compound class, then it is possible that while systematic drifts do exist, they are not strong enough to significantly influence the output. Future studies using PMF analysis with TAG compounds as input parameters will be able to specifically account for any existing systematic variations through improved calibration methods.

To note, all error and uncertainty estimates throughout this manuscript are reported as standard deviation values.

\subsection{Data reduction and analysis}

Methods for mass spectral identification, chromatogram integrations, and subsequent data processing are described in Williams et al. (2007). Particle source apportionment was performed using positive matrix factorization (PMF) to separate TAG marker organic compounds into time-covarying groups that represent multiple independent sources or transformation processes of aerosols arriving at the study site. PMF was applied using the Igor-based PMF Evaluation Panel v2.02 (Ulbrich et al., 2009). Bootstrapping of the final solution was performed using EPA PMF 1.1. Compound integra- tions have been completed using single ion abundances on the MSD. With a goal of minimizing data uncertainty, driftcorrected relative response timelines have been used as the input parameters for PMF analysis.

\subsubsection{Compound identification}

Chromatograms obtained in Riverside, CA consist of the most complex matrix of organic compounds seen by the TAG instrument to date. Figure 3 displays a typical morning rush hour chromatogram as well as a typical mid-afternoon chromatogram. While both types are composed of resolved compounds and an unresolved complex mixture (UCM), clear structural differences are observed between the two periods. Many compounds have been identified using mass spectral and retention time matches with authentic standards. Other resolved compounds have been matched to compounds found in the Palisade Complete Mass Spectral Database (600 K edition, Palisade Mass Spectrometry, Ithaca, NY). There is a high level of compound coelution from the GC column, resulting in difficult-to-identify overlapping compounds. By paying particular attention to background mass spectral subtractions, it is possible to separate overlapping compounds if they display differing mass spectral patterns. By taking advantage of these differences, we have identified approximately 300 individual organic compounds present in ambient Riverside air as measured by the TAG system. A complete compound list is provided in Table S2. Uncertainty in compound identification generally increases with additional functional groups, with the exception of compounds present in our chemical standard inventory, which have bold labels in Table S2.

A parameter used to estimate contributions to n-alkane mass from plant waxes has been included at the bottom of Table S2. These waxes display an odd-carbon preference, and can be quantified as:

$$
\begin{aligned}
C_{\mathrm{wax}} & =\sum_{n=25}^{35}\left[C_{n}-\frac{\left(C_{n-1}+C_{n+1}\right)}{2}\right], \\
n & =\text { odd integers only }
\end{aligned}
$$

where $C$ is the n-alkane concentration, $n$ is the number of carbons in the n-alkane, and $C_{\mathrm{wax}}$ is the overall contribution to $\mathrm{n}$-alkane mass from plant waxes. This estimate is derived from previous work (Simoneit, 1984).

Also included in this list are parameters serving as a rough estimate of total low volatility POA and SOA eluting through the GC system, represented by the common $\mathrm{m} / \mathrm{z} 57$ ion $\left(\mathrm{C}_{4} \mathrm{H}_{9}^{+}\right)$for POA and $m / z 43$ ion $\left(\mathrm{C}_{2} \mathrm{H}_{3} \mathrm{O}^{+}\right)$for SOA, which has been corrected for primary contributions $\left(\mathrm{C}_{3} \mathrm{H}_{7}^{+}\right)$. These parameters represent the sum of all resolved and unresolved $\mathrm{m} / \mathrm{z} 57$ and $\mathrm{m} / \mathrm{z}, 43$ ion abundances between the retention times of $40-59 \mathrm{~min}$. This retention time window contains the least volatile compounds observed by TAG, and these 


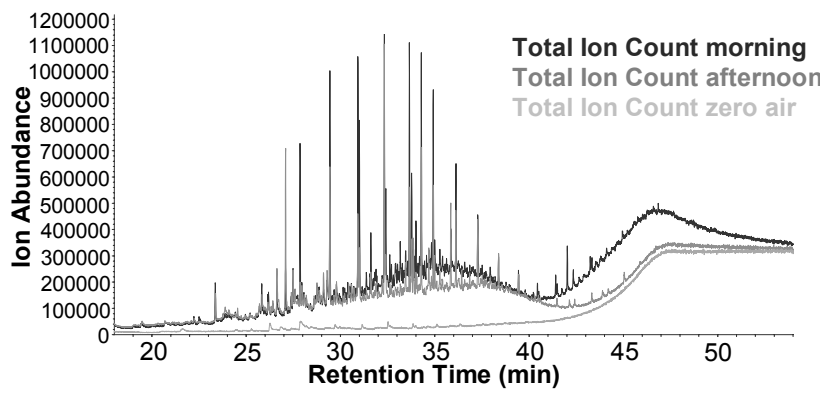

Fig. 3. Comparison of typical TAG chromatograms during SOAR. GC compound retention time (in minutes) is displayed on the $\mathrm{x}$ axis, with total ion abundance on the y-axis. The dark-shaded grey chromatogram (highest abundance) is representative of a typical morning sample (with lots of nonvolatile organic material appearing $>40 \mathrm{~min}$ ). The medium-shaded grey chromatogram is representative of a typical afternoon sample (with additional oxygenated compounds appearing <30 min). The light-shaded chromatogram is representative of a typical zero air sample.

parameters will hence be referred to as "nonvol-57" and "oxnonvol-43". Here it is assumed that all $\mathrm{m} / \mathrm{z} 57$ is from the primary fragment $\mathrm{C}_{4} \mathrm{H}_{9}^{+}$, and no $m / z 57$ comes from the oxygenated (likely secondary) fragment $\mathrm{C}_{3} \mathrm{H}_{5} \mathrm{O}^{+}$. The validity of this assumption will be tested later in the paper based on the $m / z 57$ correlation with various primary and secondary factors. The total signal at $\mathrm{m} / \mathrm{z} 57$ from the AMS shows an important contribution of $\mathrm{C}_{3} \mathrm{H}_{5} \mathrm{O}^{+}$, varying between $25 \%$ in the morning and $45 \%$ in the afternoon (Mohr et al., 2008). However, the TAG tends to favor more reduced species due to the use of a non-polar column, so these fractions should be lower in the TAG data.

The oxygenated portion of $m / z, 43$ is estimated as:

$$
\begin{aligned}
\text { ox.nonvol.43 } & =\sum_{t=40}^{59 \min } m / z 43 \\
& -\left[\left(\frac{m / z 43}{m / z 57}\right)_{\mathrm{C} 25-\mathrm{C} 31} \times \sum_{t=40}^{59 \min } m / z 57\right]
\end{aligned}
$$

where the ratio of $m / z, 43$ to $m / z 57$ as observed in $C_{25}$ through $\mathrm{C}_{31}$ alkanes (0.61) is multiplied by nonvol-57, and subtracted from the total $\mathrm{m} / \mathrm{z}, 43$ in order to eliminate the portion of $\mathrm{m} / z 43$ originating from primary hydrocarbons $\left(\mathrm{C}_{3} \mathrm{H}_{7}^{+}\right)$. The alkanes chosen for $\mathrm{m} / \mathrm{z} 43$ to $\mathrm{m} / \mathrm{z} 57$ ratios are those present within the corresponding retention time window, and the ion ratio is determined through calibrations with authentic standards. The resolved portion of $\mathrm{m} / \mathrm{z} 57$ and $\mathrm{m} / \mathrm{z} 43$ is typically around $30 \%$ of the total $\mathrm{m} / \mathrm{z} 57$ and $\mathrm{m} / \mathrm{z}, 43$ ion signal in each chromatogram, meaning the unresolved complex mixture (UCM) makes up a large fraction of the total signal. The parameters described above (i.e., nonvol-57 and ox-nonvol43) are a first step towards utilizing the wealth of information contained in TAG's UCM signal.
As an example of the differences observed amongst TAG compounds, Fig. 4 displays the summer (SOAR-1) timeline of phthalic acid (a SOA species) and 28-nor-17 $\beta(\mathrm{H})$-hopane (a POA species), plotted on a normalized scale. Here, 28nor- $17 \beta(\mathrm{H})$-hopane is elevated during the morning hours, and decreases in the afternoon. Conversely, phthalic acid is low in the morning and increases in the afternoon. This is the type of difference that will force multiple components in a PMF analysis.

\subsection{Positive matrix factorization}

PMF has been widely utilized in the atmospheric aerosol science community to separate ambient particulate matter into relatively few covarying groups of species (Xie et al., 1999; Kim et al., 2003; Maykut et al., 2003). Until recently, PMF analysis on atmospheric aerosols has mainly used trace elements, OC/EC, and inorganic ions as input. Recently, PMF analysis of high time resolution AMS OA mass spectra has been used to determine major components of atmospheric OA (Zhang et al., 2005, 2007; Ulbrich et al., 2009; Docherty et al., 2008). In these studies, several OA components are separated, including hydrocarbon-like OA, low volatility oxygenated $\mathrm{OA}$, semivolatile oxygenated $\mathrm{OA}$, and biomass burning POA (Ulbrich et al., 2009; Lanz et al., 2008; Jimenez et al., 2009). Additional chemical separation would be necessary to identify other specific OA sources.

Organic marker compounds have not typically been used in PMF analyses, since PMF requires a significant timeline of observations, which poses significant challenges and is labor intensive when acquiring organic molecular marker observations from quartz filters. One recent study on organic marker compounds, measured from quartz filters, performed a PMF analysis, but it required 2 years to collect the 120 samples used in the analysis (Jaeckels et al., 2007), another study performed PMF analysis using 99 samples over a 1 year period (Shrivastava et al., 2007), and yet another study used 932 samples over a 3 year period (Ke et al., 2008). Over an 11-day focus period, the TAG system collected 164 ambient air samples, providing a sufficient timeline to be used in the PMF analysis. Here, we report PMF analysis for two of these focus periods, one in summer and one in fall, to explore seasonal differences in organic aerosol composition. It is important to note that we are performing the first PMF source apportionment analysis based on molecular markers of total fine-mode organic aerosol mass (OA) as measured by the AMS, as opposed to previously published source apportionment of organic carbon (OC) as typically measured by OCEC analyzer (Sunset Labs), or source apportionment of black carbon (BC) (Lambe et al., 2009a). Joint PMF of the organic molecular markers from TAG and the AMS highresolution spectra is of high interest but it is outside the scope of this work. 


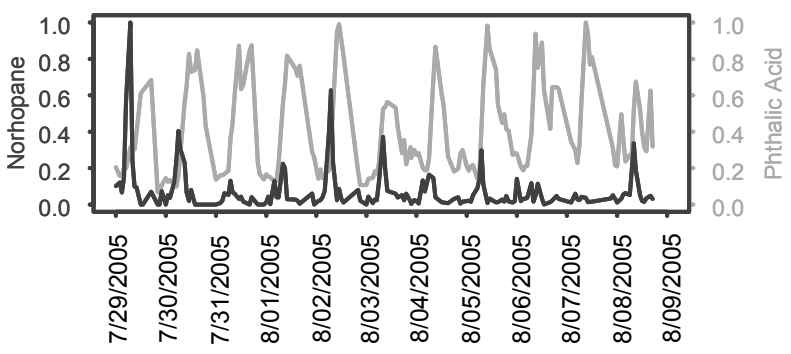

Fig. 4. Comparison of a POA species (28-nor-17 $\beta(\mathrm{H})$-hopane, in black) and a SOA species (phthalic acid, in grey) as measured by TAG during SOAR-1. Normalized abundance timelines are shown since maximum phthalic acid mass concentrations are much higher than 28-nor-17 $\beta(\mathrm{H})$-hopane concentrations. Only the particle-phase fraction is shown for each compound.

A complete description of PMF can be found in Paatero (1997) and Ulbrich (2009). Profiles are weighted based on data uncertainty. Here we have defined TAG data uncertainty using a combination of techniques. First, we define instrument precision (IP) for each compound based on a method developed by NASA researchers (Parker and Chen, 2008). By finding the peak value (i.e., mode) of the histogram of the standard deviation in consecutive data points, one can estimate a separation between instrument noise (i.e. values $<$ mode) and real signal variations (i.e. values $>$ mode) for each compound. We then incorporate this IP and an additional percentage of known uncertainty to define a total measurement uncertainty:

$s_{i j} \equiv 2 \times$ IP, if $x_{i j} \leq \mathrm{IP}$

$s_{i j} \equiv \sqrt{\left(\text { percentage } \times x_{i j}\right)^{2}+(\mathrm{IP})^{2}}, \quad$ if $x_{i j}>\mathrm{IP}$,

where $s_{i j}$ and $x_{i j}$ are respectively the total uncertainty and concentration in the $j$-th species during the $i$-th hour of study. A similar weighting of uncertainty based on observed concentrations is used in other versions of PMF (EPA PMF 1.1 User's Guide). For the PMF results reported here, a known $10 \%$ uncertainty for all input parameters (Williams et al., 2006, 2007; Kreisberg et al., 2009) was applied in Eq. (3b). Here we are accounting for the known TAG uncertainty based on the observed reproducibility (10\% uncertainty) as determined in this study by Kreisberg et al. (2009) and as has been observed in previous studies by Williams et al. (2006, 2007), and derived instrument precision (using NASA method (Parker and Chen, 2008)). Reproducibility accounts for uncertainty in sample transfer, detection, and the operator's ability to reproducibly integrate the final compound signal during the data analysis. The NASA method is used to distinguish whether signal variations are large enough to be considered a real change in signal or if the signal variations are so small that they should be considered instrument noise. The total uncertainty for each compound as determined here (i.e., $s_{i j}$ ) is thought to err on the side of a high uncertainty estimate.
PMF minimizes the sum of squares of error-weighted model-measurement deviations. This sum is referred to as the $Q$ value. $Q$ is derived in the robust mode, meaning that outlying values have been reduced to prevent their influence on the fitting of contributions and profiles. $Q$-expected $\left(Q_{\exp }\right)$ is calculated as:

$Q_{\exp } \equiv(i \times j)-p \times(i+j)$

where $j$ is the number of input parameters, $i$ is the number of hourly samples, and $p$ is the number of factors obtained. If the model is appropriate for the input data and the errors have been estimated properly, then $Q$ should be approximately equal to $Q_{\text {exp. }}$. The model has serious problems if these $Q$ values differ by an order of magnitude or greater (EPA PMF 1.1 User's Guide), although as this comparison is only a guideline and not a rule, uncertainties should not be manipulated in order to create $Q / Q_{\exp }=1$. The solution space can also be explored by varying fpeak (a tool used to explore rotations of the solutions of a given number of factors) and seeds (a tool used to choose different random starts or initial values for the PMF algorithm) (Ulbrich et al., 2009), and will be performed here.

EPA PMF 1.1 offers a bootstrapping tool combined with a rotational freedom method to estimate uncertainties in model results. The results of this test inform the operator of the robustness of the specific factor profiles defined by the original base case model by comparing these profiles to the profiles defined in a series of additional runs (bootstraps). Here, we use 300 bootstraps, all with random starting points, and match only profiles with correlations $(r)$ greater than 0.6 . A bootstrapping technique is currently being developed for the Igor-based PMF Evaluation Panel, but was not completed before the analysis performed for this paper.

Only the particle-phase portion of TAG compounds (i.e., gas-phase subtracted) has been included in the PMF analyses. Since fewer filtered ambient (i.e., gas-phase) samples were taken than ambient (i.e., gas + particle) samples, gas-phase variability is missed when interpolating the gasphase timeline onto the ambient timeline. However, time resolution is lost by interpolating the ambient timeline onto the gas-phase timeline. As a solution, we have interpolated the gas-phase timeline onto the ambient timeline, keeping the higher time resolution, and have only included compounds in PMF analysis that meet the following requirements: compounds must on average be $>35 \%$ in the particle phase (a value determined through a PMF sensitivity analysis, wherein PMF solutions were stabilized by eliminating compounds that were dominantly in the gas-phase), to eliminate very large gas-phase subtractions, and each compound's particle-phase timeline must have a correlation $>0.7$ with its ambient (gas + particle) timeline, indicating that most of the variability is conserved after subtracting the gas-phase portion. TAG compounds failing to meet this criteria have been eliminated from our PMF analysis. 
These criteria have been set to minimize artificial influence on particle-phase variations due to large gas-phase subtractions. Additionally, in this study, we are interested specifically in particle sources, not general pollutant sources. In our tests, we observed that the inclusion of the particle-phase fraction of dominantly gas-phase species propagated to additional noise and even false factors in the PMF results. This is due to near-zero particle-phase signals that look more like noise than real signal (e.g., see alkane example in Fig. S2). By testing dozens of different cutoff criteria, the previous values ( $>35 \%$ particle-phase, correlation $>0.7 \mathrm{w} /$ total signal variability) were found to distinguish the point where a compound's particle-phase signal could be viewed as real signal as opposed to a noisy remainder from a large subtraction.

The sum of the concentrations of all the species measured by the TAG are estimated to be less than $20 \%$ of the AMS OA concentration on average. In a recent filter-based chemical mass balance $(\mathrm{CMB})$ analysis performed during SOAR, less than $5 \%(0.5 \%)$ of the OA mass was captured by the measured tracers (tracers used in CMB analysis) (Docherty et al., 2008). Thus rather than assigning OA mass to each factor as the sum of the species concentrations, the OA mass is taken as that assigned to each component through a multivariate fit of PMF factors to total OA. This is different from traditional CMB analysis where the $\mathrm{OC} /$ tracer ratios are part of the source profile information used in the analysis. This method of apportioning OA mass to the PMF components is a key uncertainty of the current approach, as effectively the time-series of $\mathrm{OA}$ is being projected in to the time-series of the individual factors defined by the TAG, and the problem is underdetermined. To estimate the sensitivity of the multivariate fit to minor random changes in OA concentrations, we introduce noise to total OA and fit our factors to the new OA values. For each season, we performed 10 different fits to adjusted OA values using Gaussian random noise of $0.1 \mu \mathrm{g} \mathrm{m} \mathrm{m}^{-3}+10 \% \operatorname{sqrt}(\mathrm{OA})$. The noise introduced in the OA concentration for this procedure represents the precision of the AMS OA measurement, which is estimated as a minimum value at low concentrations $\left(0.1 \mu \mathrm{g} \mathrm{m}^{-3}\right)$ plus additional noise which is proportional to the square root of the OA concentration (Drewnick et al., 2009). Fitting errors are incorporated in the final estimates of PMF factor's contributions to OA mass concentrations, in combination with propagated TAG and AMS measurement errors.

Since the AMS measures $\mathrm{PM}_{1}$ and the TAG measures $\mathrm{PM}_{1.5}$, the assumption must be made that the organics observed by the TAG system are dominantly in the $\mathrm{PM}_{1}$ size range, and that much of the aerosol mass in the 1.0-1.5 $\mu \mathrm{m}$ is either inorganic or consistent with $\mathrm{PM}_{1}$ speciation. There is evidence from size-resolved ATOFMS measurements to suggest that the major sources to aerosol mass in the supermicron range are Sea Salt and Dust particles, both high in inorganic mass.
The AMS data contained several gaps within the fall focus period. To obtain total $\mathrm{PM}_{1} \mathrm{OA}$ mass concentrations during these periods, AMS $\mathrm{PM}_{1} \mathrm{OA}$ was estimated using correlations between the AMS and a California Air Resources Board beta attenuation monitor (BAM, measuring $\mathrm{PM}_{2.5}$ ) at the Rubidoux monitoring station located approximately $10 \mathrm{~km}$ northwest of the SOAR site. Throughout the fall sampling period, a strong correlation between $\mathrm{BAM} \mathrm{PM}_{2.5}$ and AMS $\mathrm{PM}_{1}$ OA was observed $\left(r^{2}=0.70\right.$, slope $\left.=0.19\right)$. AMS $\mathrm{PM}_{1} \mathrm{OA}$ was estimated using a combination of techniques. For consecutive missing data points, BAM concentrations were scaled down based on the relationship between BAM and AMS OA (Eq. 5a). To improve fits for single missing data points, OA was estimated by multiplying the BAM measurements to the product of the slope obtained from comparing the total mass measurements and the average OA contribution to AMS total $\mathrm{PM}_{1}$ measured before and after the gaps (Eq. 5b). The following equations are used to complete the fall OA timeline:

$\mathrm{PM}_{1} \mathrm{OA}=\left(m \cdot \mathrm{PM}_{2.5}\right)+b$, for $>1$ missing value $(\mathrm{MV})(5 \mathrm{a})$

$$
\begin{aligned}
\mathrm{PM}_{1} \mathrm{OA} & =\mathrm{PM}_{2.5} \cdot\left(\frac{\mathrm{PM}_{1}}{\mathrm{PM}_{2.5}}\right) \cdot\left(\left[\left(\frac{\mathrm{PM}_{1} \mathrm{OA}_{\text {before }}}{\mathrm{PM}_{1 \text { before }}}\right)\right.\right. \\
& \left.\left.+\left(\frac{\mathrm{PM}_{1} \mathrm{OA}_{\text {after }}}{\mathrm{PM}_{1 \text { after }}}\right)\right] \div 2\right), \text { for } 1 \mathrm{MV}
\end{aligned}
$$

where $\mathrm{PM}_{2.5}$ is BAM measurements, $\mathrm{PM}_{1}$ is total AMS signal, $\mathrm{PM}_{1} \mathrm{OA}$ is OA measured by AMS, "before" and "after" refer to AMS data points on either side of missing data point. The correlation between BAM $\mathrm{PM}_{2.5}$ and $\mathrm{AMS} \mathrm{PM}_{1} \mathrm{OA}$ is slightly improved $\left(r^{2}=0.74\right)$ by excluding data points that are greater than or less than one standard deviation from the mean of their ratio (BAM $\mathrm{PM}_{2.5} / \mathrm{AMS} \mathrm{PM}_{1} \mathrm{OA}$ ), which acts to filter out local events that do not impact the other site. This relationship is used for values $m(=0.19)$ and $b(0.93)$ in Eq. (5a), and can be seen in Supplement (Fig. S3). The resulting complete timeline for $\mathrm{PM}_{1}$ OA during SOAR-2 is also displayed in Supplement (Fig. S4). Original AMS measurements account for $55 \%$ of the reconstructed timeline, $40 \%$ of the timeline is derived by Eq. (5a), and $5 \%$ from Eq. (5b).

\subsubsection{Identification of $\mathrm{OA}$ components}

PMF analyses were performed on 124 TAG compounds for the summer period and 141 TAG compounds for the fall period (Table $\mathrm{S} 2$ ), along with $C_{\mathrm{wax}}$ (summer only), nonvol-57, and ox-nonvol-43, over the focus periods of $29 \mathrm{July}-8 \mathrm{Au}-$ gust, and 4 November-14 November. Conditions during the summer focus period were representative of those during the complete campaign with respect to seasonal meteorological trends (e.g., wind speed, wind direction), and atmospheric composition (e.g., odd oxygen $\left(\mathrm{O}_{\mathrm{x}}\right)$, carbon monoxide $(\mathrm{CO})$, AMS $\mathrm{PM}_{1} \mathrm{OA}$ ) as observed over the entire summer study (Fig. 5a). Also the summer campaign was representative 
Summer Focus Period

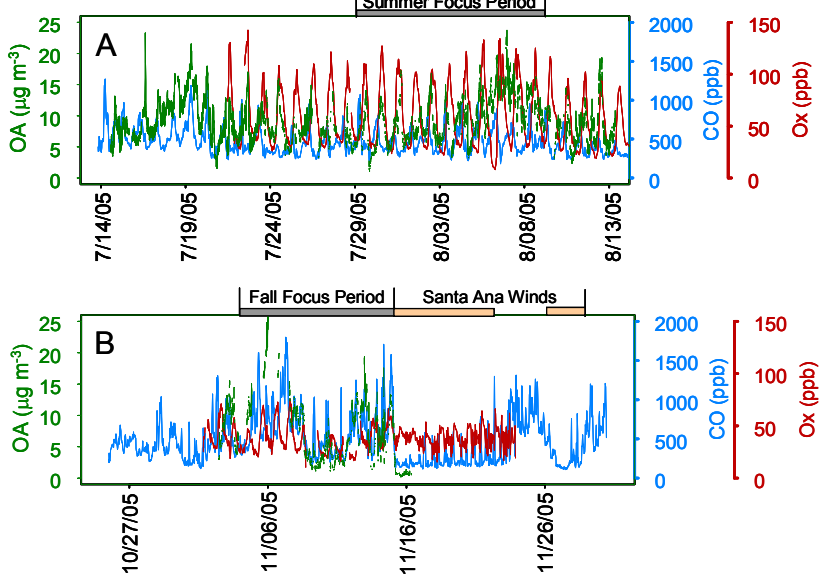

Fig. 5. AMS $\mathrm{PM}_{1}$ organics, carbon monoxide $(\mathrm{CO})$, and odd oxygen $\left(\mathrm{O}_{\mathrm{x}}\right)$ concentrations during SOAR 2005. (A) The summer period (29 July-8 August) displays regular diurnal oxidation trends. The summer focus period (outlined in grey) is consistent with the general trend of the entire summer study. (B) The fall period (4 November-14 November) is dominated by meteorological "events", with lower $\mathrm{O}_{\mathrm{x}}$ concentrations than observed in summer. The fall focus period (outlined in grey) is representative of a period high in particulate concentrations and $\mathrm{CO}$ concentrations.

of typical conditions during previous years (Docherty et al., 2008). However, the full fall study period was highly influenced by meteorological events (e.g., Santa Ana Winds), while the chosen focus period exhibited larger urban influence (Fig. 5b), and excludes the period with Santa Ana winds providing less polluted desert air to the site.

Additional gas and particle-phase measurements that were not used in the PMF analysis contribute supporting information to help verify the identification of each factor based on their variability and known sources. Odd oxygen $\left(\mathrm{O}_{\mathrm{x}}=\mathrm{O}_{3}+\mathrm{NO}_{2}\right)$ is used as a tracer for aged urban pollution. Using $\mathrm{O}_{\mathrm{x}}$ instead of $\mathrm{O}_{3}$ as a tracer removes the effect of titration of $\mathrm{O}_{3}$ by $\mathrm{NO}$ (Herndon et al., 2008). $\mathrm{CO}$ is used as a tracer of primary combustion. Note that production of $\mathrm{CO}$ from the oxidation of VOCs has been shown to make a very small contribution to ambient levels in Southern California (Griffin et al., 2007). Correlations of selected parameters to the TAG-defined factors are reported in Table 2. Included are $\mathrm{O}_{\mathrm{x}}, \mathrm{CO}$, gas-phase $\mathrm{H}_{2} \mathrm{O}$, gas-phase VOCs, EC, OC, AMS measurements of OA, sulfate, nitrate, ammonium, and chloride, and time series of particle counts derived from cluster analysis of ATOFMS single particle data (representative of different single particle sources and transformation processes). These ATOFMS single-particle types (separated by submicron and supermicron sizes) included two different types of aged organics not associated with sulfate (AgedOC), one type of aged organics containing sulfate (AgedOCSO4), organics containing elemental carbon (ECOC), organics containing both elemental carbon and sulfate (ECOCSO4), el- emental carbon alone (EC), amines (Amine), aged sea salt particles (AgedSS), dust particles (Dust), vanadium-rich particles (V), biomass particles rich in potassium (Biomass), and particles rich in ammonium nitrate (NH4NO3).

We label OA components (factors) based on matches of TAG compounds, measured VOCs, and other gas-phase compounds to known source profiles, mass concentrations of major inorganic components (e.g., ammonium, chloride, nitrate, and sulfate) of $\mathrm{PM}_{1}$ as measured by the AMS, and ATOFMSdefined single-particle clusters. This information, along with meteorological parameters such as wind speed and direction was used to further define sources of each identified OA component. For example, during the summer, OA components for which sources originate from the west during daytime high winds are being transported from further distances as the boundary layer rises and atmospheric mixing increases, whereas components having higher contributions at night strongly suggest local sources as they are encountered under conditions of variable wind direction and low wind speed during periods of strong atmospheric stability and a shallow boundary layer.

With PMF analysis, it is left to the operator to interpret the underlying source(s) or process(es) responsible for the appearance of each identified factor. In this study, we relate each factor to either an aerosol source type in the case of primary aerosols (e.g., vehicle emissions, biomass burning) or formation process(es) in the case of secondary aerosol formation. Since ambient air composition in Riverside is influenced by a wide range of local and regional, biogenic and anthropogenic, primary and secondary organic aerosol sources, no statistical tool is capable of a precise separation of all source types. PMF works to separate the dominant contributing factors from which aerosol sources can be inferred. Each factor has small contributions from other source types which have overlapping or similar composition profiles (Ulbrich et al., 2009). Here, we attribute each factor based on the source type that displays the highest influence on that factor.

It is the authors' intention that names appointed to factors herein are given in the most general terms possible, and not intended to over-explain our understanding of the guiding influences on each PMF component. As is true for AMS PMF analyses, the components defined here are not expected to be universal of all studies, and the naming of TAG PMF components are meant to evolve with our understanding of the components, just as has been done for AMS PMF components. For example, oxygenated OA components OOA-1 and OOA-2 (Lanz et al., 2007) have recently evolved to low volatility (LV)-OOA and semivolatile (SV)-OOA ( $\mathrm{Ng}$ et al., 2009; Jimenez et al., 2009), respectively.

\section{Results}

The variability in the data was best explained by 9 factors for the summer period and 7 factors for the fall period through the PMF analysis using the defined input parameters (see 
Table 2. Highest Correlations $(r>0.4)$ between TAG Factors and Other Relevant Parameters.

\begin{tabular}{|c|c|c|c|c|c|}
\hline & Summer & Fall & & Summer & Fall \\
\hline \multicolumn{2}{|c|}{ Meteorological Parameters: } & & \multicolumn{2}{|c|}{ Particle-Phase Parameters: } & \\
\hline air temperature & SOA3 & RPA & OC & SOA2 & NA \\
\hline sunlight & SOA1 & RPA & EC & LV & NA \\
\hline windspeed & SOA3 & RPA & & & \\
\hline relative humidity & $\mathrm{SOA} 4+\mathrm{SV}$ & $\mathrm{SOA}+\mathrm{SV}$ & AMS: & & \\
\hline \multirow[t]{2}{*}{ atmos. pressure } & & $\mathrm{BB}$ & Organics & SOA2 & $\mathrm{SOA}+\mathrm{FC} 2$ \\
\hline & & & $\mathrm{SO}_{4}^{2-}$ & FC & SOA \\
\hline \multicolumn{2}{|c|}{ Gas-Phase Parameters: } & & $\mathrm{NO}_{3}^{-}$ & SOA2 & SOA \\
\hline $\mathrm{O}_{\mathrm{x}}$ & SOA3 & SOA & $\mathrm{NH}_{4}^{+}$ & SOA2 & SOA \\
\hline $\mathrm{O}_{3}$ & SOA3 & & Chloride & $\mathrm{FC}$ & SOA \\
\hline $\mathrm{CO}$ & LV & LV & & & \\
\hline $\mathrm{H}_{2} \mathrm{O}$ & $\mathrm{FC}$ & & ATOFMS: & & \\
\hline \multicolumn{2}{|c|}{ VOC GC-MSD-FID: } & & $\begin{array}{l}<1 \mu \mathrm{m} \\
\text { subAgedOC1 }\end{array}$ & RPA & $\mathrm{SOA}+\mathrm{FC} 2$ \\
\hline o-xylene & $\mathrm{BB}$ & LV & subAgedOCSO4 & SOA2 & $\mathrm{SOA}+\mathrm{FC} 2$ \\
\hline benzene & LV & $\mathrm{SOA}+\mathrm{FC} 2$ & subAgedOC2 & & \\
\hline toluene & $\mathrm{BB}$ & $\mathrm{SOA}+\mathrm{FC} 2$ & subECOCSO4 & SOA2 & $\mathrm{SOA}+\mathrm{FC} 2$ \\
\hline propane & LV & $\mathrm{SOA}+\mathrm{FC} 2$ & subECOC & $\mathrm{FC}$ & $\mathrm{SOA}+\mathrm{FC} 2$ \\
\hline hexane & LV & $\mathrm{SOA}+\mathrm{FC} 2$ & subEC & & $\mathrm{SOA}+\mathrm{FC} 2$ \\
\hline propene & LV & $\mathrm{LV}$ & subAmine & $\mathrm{SOA}+\mathrm{FC} 1$ & \\
\hline butene & $\mathrm{FC}$ & LV & subV & SOA2 & $\mathrm{SOA}+\mathrm{FC} 2$ \\
\hline propyne & LV & LV & subBiomass & SOA2 & $\mathrm{SOA}+\mathrm{FC} 2$ \\
\hline methylpentane & LV & $\mathrm{SOA}+\mathrm{FC} 2$ & subAgedSS & SOA3 & \\
\hline methylpropanal & $\mathrm{BB}$ & $\mathrm{SOA}+\mathrm{FC} 2$ & subDust & SOA2 & LV \\
\hline isopropanol & LV & & subNH4NO3 & & \\
\hline acetonitrile & $\mathrm{BB}$ & LV & subOther & & $\mathrm{SOA}+\mathrm{FC} 2$ \\
\hline propanal & SOA2 & SOA & $>1 \mu \mathrm{m}$ & & \\
\hline acetone & SOA2 & $\mathrm{SOA}+\mathrm{FC} 2$ & superAgedOC1 & $\mathrm{FC}$ & $\mathrm{SOA}+\mathrm{FC} 2$ \\
\hline methyl ethyl ketone & SOA2 & SOA & superAgedOCSO4 & SOA2 & $\mathrm{SOA}+\mathrm{FC} 2$ \\
\hline pentanal & SOA3 & $\mathrm{SOA}+\mathrm{FC} 2$ & superAgedOC2 & & \\
\hline isoprene & SOA3 & RPA & superECOCSO4 & SOA2 & $\mathrm{SOA}+\mathrm{FC} 2$ \\
\hline methacrolein & SOA3 & RPA & superECOC & $\mathrm{FC}$ & $\mathrm{SOA}+\mathrm{FC} 2$ \\
\hline methyl vinyl ketone & SOA3 & $\mathrm{SOA}+\mathrm{FC} 1$ & superEC & FC & $\mathrm{SOA}+\mathrm{FC} 2$ \\
\hline a-pinene & $\mathrm{BB}$ & LV & superAmine & & \\
\hline \multirow[t]{5}{*}{ b-pinene } & $\mathrm{BB}$ & LV & superV & SOA2 & SOA \\
\hline & & & superBiomass & SOA2 & $\mathrm{SOA}+\mathrm{FC} 2$ \\
\hline & & & superAgedSS & SOA1 & \\
\hline & & & $\begin{array}{l}\text { superDust } \\
\text { superNH4NO3 }\end{array}$ & SOA2 & LV \\
\hline & & & superOther & FC & $\mathrm{SOA}+\mathrm{FC} 2$ \\
\hline
\end{tabular}

Notes: Summer PMF factors all have correlations $<0.35$ with other summer PMF factors, and fall PMF factors have correlations $<0.24$ with other fall PMF factors. Also, the observation that CO and EC have highest correlation with LV only implies that there is more dramatic variability of CO and EC from local sources as opposed to regional variability, not that regional variability of $\mathrm{CO}$ and $\mathrm{EC}$ has been removed or does not exist.

Table 1 for a full list of TAG PMF components and their abbreviations). Additional factors do not help to explain additional overall variability. Additional factors either apportion mass to less unique factors with contributions from all compound classes, or if many factors are used, the signal from major factors is split into multiple factors of nearly identical composition and diurnal variability. A similar "fac- tor splitting" phenomenon has been discussed for PMF of AMS spectra by Ulbrich et al. (2009). Fewer factor solutions, while still meaningful if the operator can determine all sources that may contribute to each factor, do not maximize our resolution of potential contributors to total OA, which is our goal in this study. 
Other PMF solutions are contrasted in Supplement (Fig. S5). In the summer period, a 7-factor solution does not resolve the SOA1 or FC components (see Table 1 for factor abbreviation definitions). The 8-factor solution does not resolve the SOA1 component, which does have a unique chemical profile from the other SOA components. The 9factor solution is discussed in great detail in the following section, and the 10-factor solution removes OA mass contributions from SOA3 and SOA4 +SV while producing a 10th component that cannot be matched to a known source profile, does not have a clear diurnal trend, and is composed of a mixture of hydrocarbons and oxygenated compounds. In the fall period, a 5-factor solution does not resolve the RPA and BB component. The 6-factor solution does not resolve the RPA component, which does have a unique chemical profile and matches the same component that was observed in the summer period. The 7-factor solution is discussed in great detail later in this manuscript, and the 8-factor solution produces an 8th component that cannot be matched to a known source profile, does not display a diurnal trend, and is composed of a mixture of hydrocarbons and oxygenated compounds.

Several figures are provided to further explore PMF results (using the 9-factor summer solution and the 7-factor fall solution). Separated by season, factor profiles (i.e., loadings of each TAG compound into a specific PMF component) are shown in Fig. 6 (summer) and Fig. 7 (fall). Timeseries of all PMF components are shown in Fig. 8 (summer) and Fig. 9 (fall). Individual timeseries and diurnal plots for PMF components are shown in Fig. 10 (summer) and Fig. 11 (fall), and PMF component concentration rose plots (i.e., direction in which component arrives to the site) are displayed in Fig. 12 (summer) and Fig. 13 (fall).

\subsection{SOAR-1 (summer) PMF Results}

The $Q / Q_{\exp }$ value for a 9 factor solution with fpeak set to 0 (i.e., no rotation) is found to be 2.9 , which is within a reasonable range according to the EPA PMF 1.1 User's Guide. Varying fpeak between \pm 2 in increments of 0.5 displays a minimum $Q / Q_{\exp }$ at fpeak $=0$, and using over 60 seeds (starting points) produces identical $Q / Q_{\exp }$ values for all solutions (see Supplement, Fig. S6). EPA PMF bootstrapping efforts confirm stable model results. Of 300 bootstraps, and of the resulting 2700 factors, only 124 factors (i.e., 4.6\%) did not match the factor profiles defined in the base case. Timeseries for all factors displayed a fit of $r^{2}=1$ between the 9factor solution from EPA PMF 1.1 and from the Igor-based PMF Evaluation Panel v2.02.

\subsubsection{Factors 1-4: SOA1, SOA2, SOA3, and SOA4 + Semivolatile (SV)}

We define Factor 1 as SOA type 1 (SOA1). This component increases during the daytime as observed in a diurnal plot (Fig. 10), arrives to the site from the west ac- cording to concentration rose plots shown in Fig. 12. This factor is largely composed of oxygenated species (Fig. 6, Table S2), including significant contributions from ketones and acids (heptadecanone, octadecanone, dodecanoic acid), esters (isopropylpalmitate, dehydroabietic acid methyl ester), esters of aromatic carboxylic acids (phthalates), and oxygenated nitrogen-containing organic compounds (indoloquinoline, penoxaline, nitrophenylbenzenamine), along with several hydrocarbons. Some of these species have both primary and secondary sources. There is a high correlation between this factor and sunlight (Table 2), further indicating this OA component is largely derived through secondary processes. The factor profile and time series of SOA1 are shown in Figs. 6 and 8, respectively. Individual factor time series and average diurnal profiles are shown in Fig. 10.

Table S2, Column 8 identifies the PMF factor with which compounds identified by the TAG (particle-phase signal only) have highest correlation during the summer sampling period. Table S2 includes all such compounds that were and were not included in the PMF analysis. Of those that were not included in the PMF analysis (i.e., semivolatile compounds favoring the gas-phase), those that have highest correlations with SOA1 aerosol again include mostly oxygenated species along with a few hydrocarbons. Some correlations worth mentioning include several ketones, the oxygenated PAH anthraquinone, and several furanones, which have been reported to be produced through oxidation of alkenes and aromatic hydrocarbons (Forstner et al., 1997a, b). Other compounds with high correlation with this factor include aldehydes, acids, esters, and esters of aromatic carboxylic acids. Average contributions from each factor to total OA mass concentrations can be found in Table 3, and will be further discussed in the following Sects. 3.4 and 3.5.

We define Factor 2 as SOA type 2 (SOA2). Similar to SOA1, this component also has highest contributions during the daytime (Fig. 10) when the wind is arriving from the west (Fig. 12) at elevated wind speeds. SOA2 contributes highest to OA mass concentrations between 08:00 a.m.-12:00 p.m. pacific standard time (PST) (09:00 a.m.-01:00 p.m. local time) as observed in Fig. 10. Highest contributions to this factor are almost exclusively from oxygenated species (Fig. 6, Table S2), including large contributions from phthalic acid and two methylated phthalic acids (3-methylphthalic acid and 4-methylphthalic acid), oxygenated PAHs (xanthone, cyclopenta(d, e, f)phenanthrenone), oxygenated nitrogen species (4-nitrophenol), and a di-ketone (dimethylisobenzofurandione). Many of these compounds are formed through the photooxidation of gas-phase precursors (Wang et al., 2006, 2007; Harrison et al., 2005), and are thought to serve as marker compounds for SOA formation (Fine et al., 2004a). Species not included in the PMF analysis having high correlations with this factor include oxygen-containing acids and ketones including benzoic acid, phenylacetic acid, dihydro-5-butyl-2(3H)furanone, 


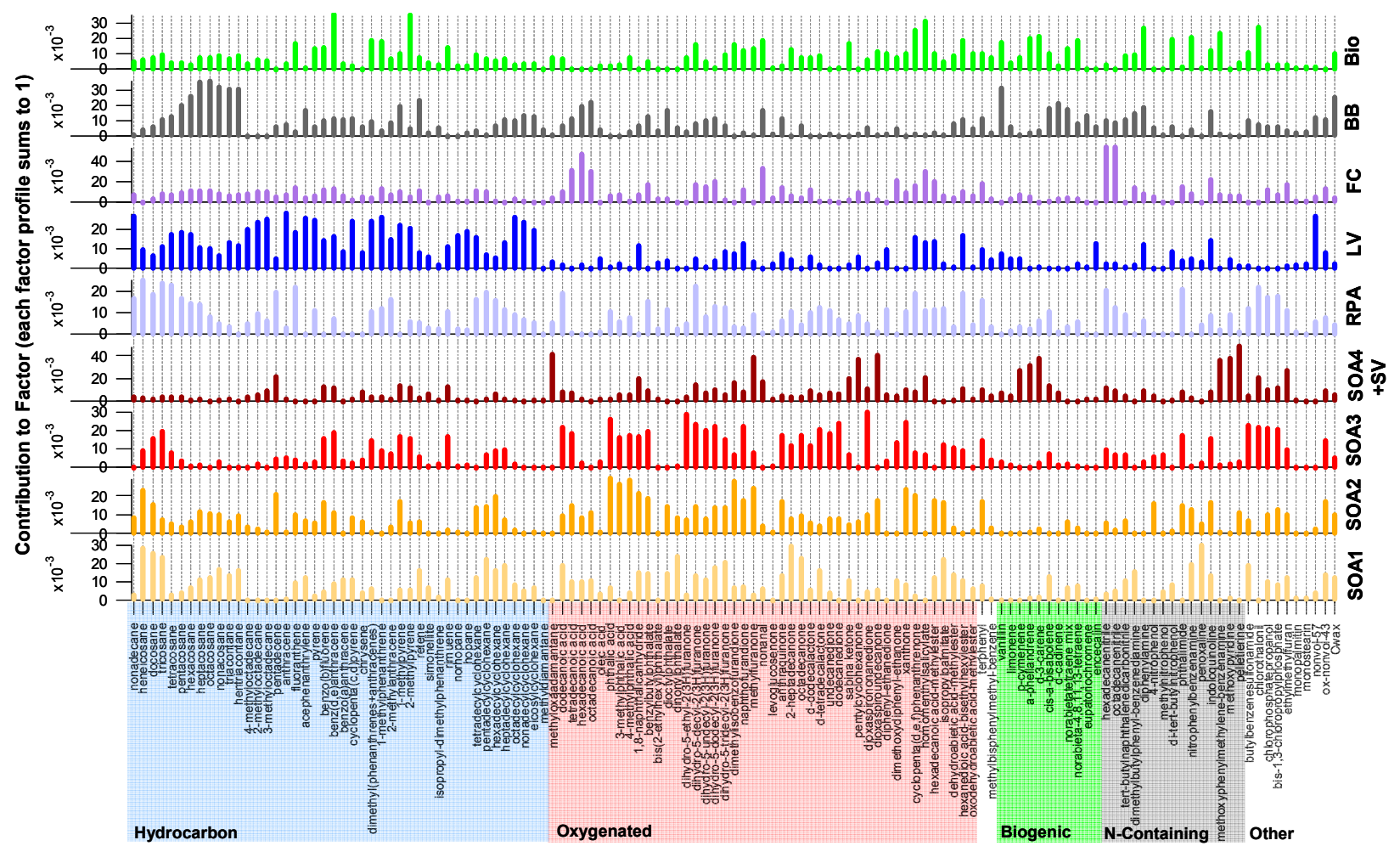

Fig. 6. Summer PMF profiles. Compounds are generally grouped by hydrocarbons (compound names with blue background), oxygenated species (red background), biogenics (green background), nitrogen-containing compounds (grey background), and others (white background), respectively. Total compound contributions to each of the 9 factor profiles sums to a value of 1 .

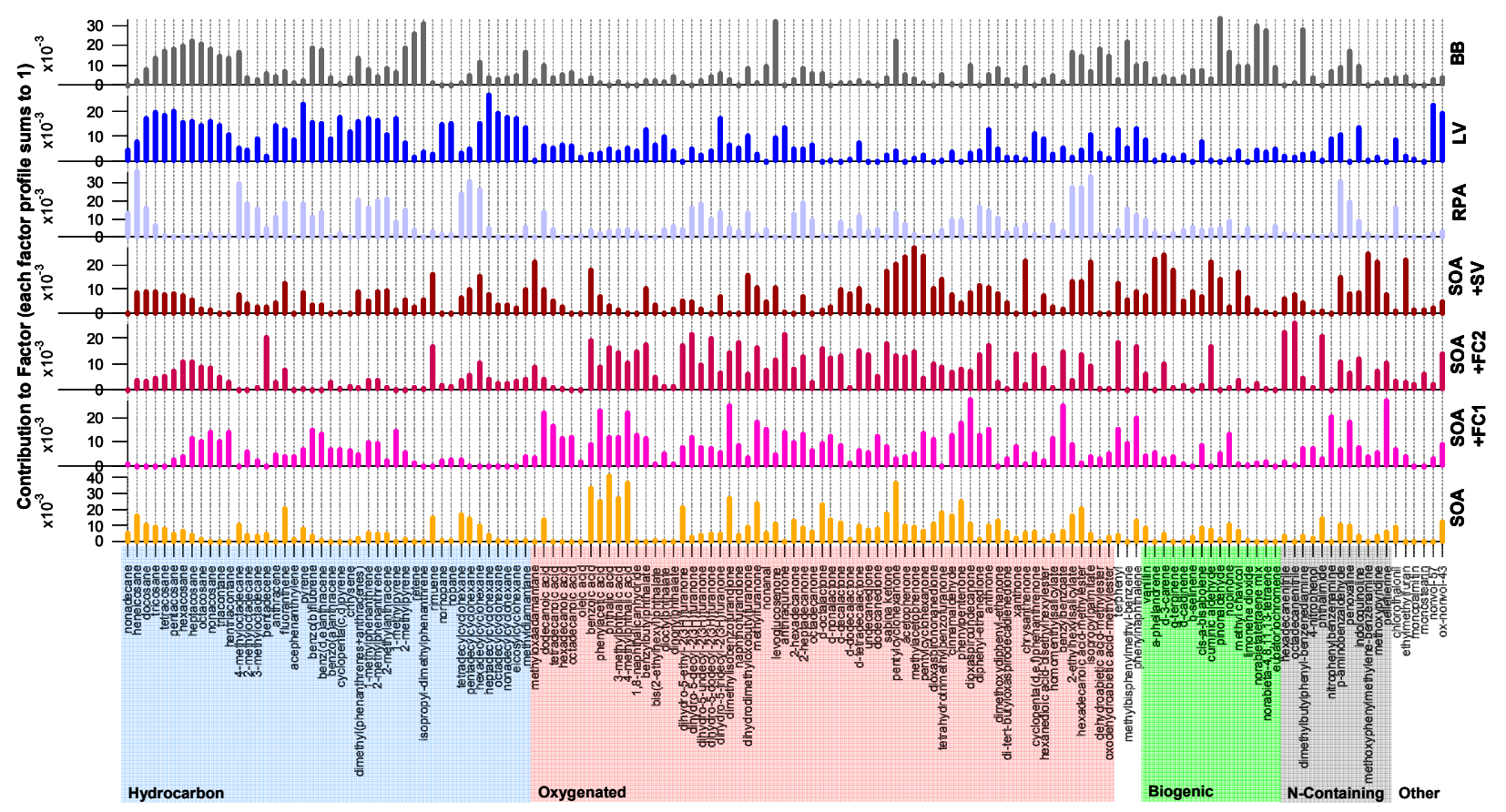

Fig. 7. Fall PMF profiles. Compounds are generally grouped by hydrocarbons (compound names with blue background), oxygenated species (red background), biogenics (green background), nitrogen-containing compounds (grey background), and others (white background), respectively. Total compound contributions to each of the 7 factor profiles sums to a value of 1 . 
Table 3. Average Factor Concentrations and Contributions to OA during SOAR 2005.

\begin{tabular}{|c|c|c|c|c|c|}
\hline \multirow[t]{2}{*}{ Summer } & \multicolumn{5}{|c|}{ Fall } \\
\hline & $\begin{array}{l}\text { Average Concentration } \\
\qquad\left(\mu \mathrm{g} \mathrm{m}^{-3}\right)\end{array}$ & $\begin{array}{r}\text { Contrib. to Total OA } \\
(\%)\end{array}$ & & $\begin{array}{l}\text { Average Concentration } \\
\qquad\left(\mu \mathrm{g} \mathrm{m}^{-3}\right)\end{array}$ & $\begin{array}{r}\text { Contrib. to Total OA } \\
(\%)\end{array}$ \\
\hline SOA1 & $0.14 \pm 0.04$ & 1.5 & SOA & $3.40 \pm 0.72$ & 38.4 \\
\hline SOA2 & $2.24 \pm 0.44$ & 23.9 & $\mathrm{SOA}+\mathrm{FC} 1$ & $0.77 \pm 0.20$ & 8.7 \\
\hline SOA3 & $2.18 \pm 0.41$ & 23.2 & $\mathrm{SOA}+\mathrm{FC} 2$ & $2.21 \pm 0.47$ & 25 \\
\hline $\mathrm{SOA} 4+\mathrm{SV}$ & $1.87 \pm 0.39$ & 19.9 & $\mathrm{SOA}+\mathrm{SV}$ & $0.51 \pm 0.13$ & 5.8 \\
\hline RPA & $0.85 \pm 0.17$ & 9 & RPA & $0.41 \pm 0.11$ & 4.6 \\
\hline LV & $0.27 \pm 0.07$ & 2.9 & LV & $0.49 \pm 0.13$ & 5.5 \\
\hline $\mathrm{FC}$ & $0.98 \pm 0.22$ & 10.4 & $\mathrm{BB}$ & $0.95 \pm 0.23$ & 10.8 \\
\hline BB & $0.64 \pm 0.15$ & 6.8 & RemainingOA & $0.11 \pm 0.03$ & 1.2 \\
\hline Bio & $0.11 \pm 0.03$ & 1.2 & & & \\
\hline RemainingOA & $0.11 \pm 0.03$ & 1.1 & & & \\
\hline
\end{tabular}

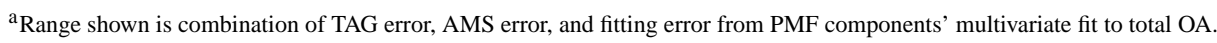

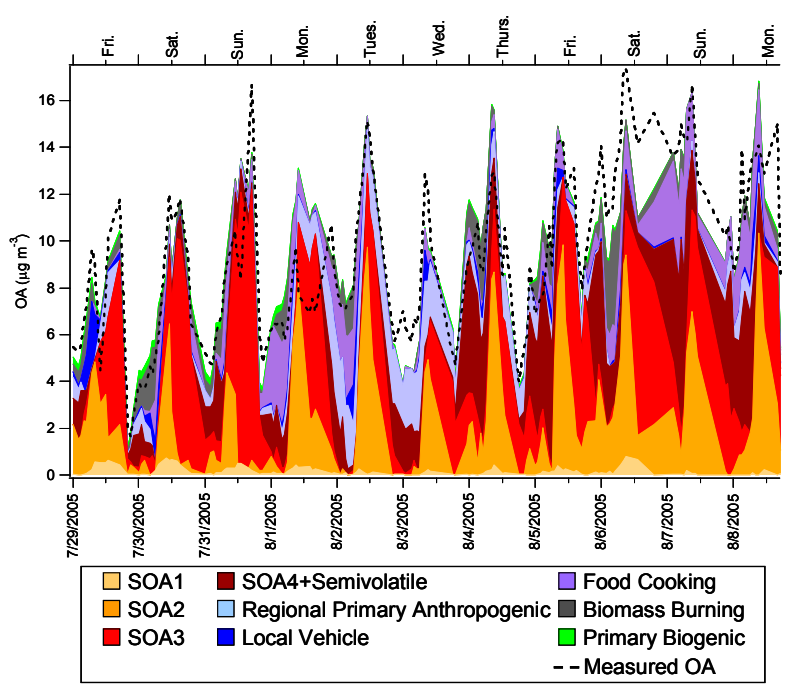

Fig. 8. Factor contributions to $\mathrm{PM}_{1}$ organic aerosol mass concentrations during the summer focus period (29 July-8 August). Dates are labeled at the beginning (midnight PST) of that day.

phenylpentenone (Table S2). Measurements made by other instrumentation that are highly correlated with SOA2 include acetone, propanal, methyl ethyl ketone (MEK), and total particle-phase $\mathrm{OC}, \mathrm{OA}, \mathrm{NO}_{3}^{-}, \mathrm{NH}_{4}^{+}$(Table 2), some of which have both secondary and primary origins.

We define Factor 3 as SOA type 3 (SOA3). Similar to the other SOA identified components, SOA3 has highest contributions during the daytime (Fig. 10) when the wind is arriving from the west (Fig. 12) at very high wind speeds. SOA3 contributes highest to OA mass concentrations later in the afternoon, between 01:00 p.m.-06:00 p.m. PST (02:00 p.m.07:00 p.m. local time), and may have had more time to age in the atmosphere compared to SOA1 and SOA2. Again, contributions from oxygenated species dominate this factor (Fig. 6, Table S2).

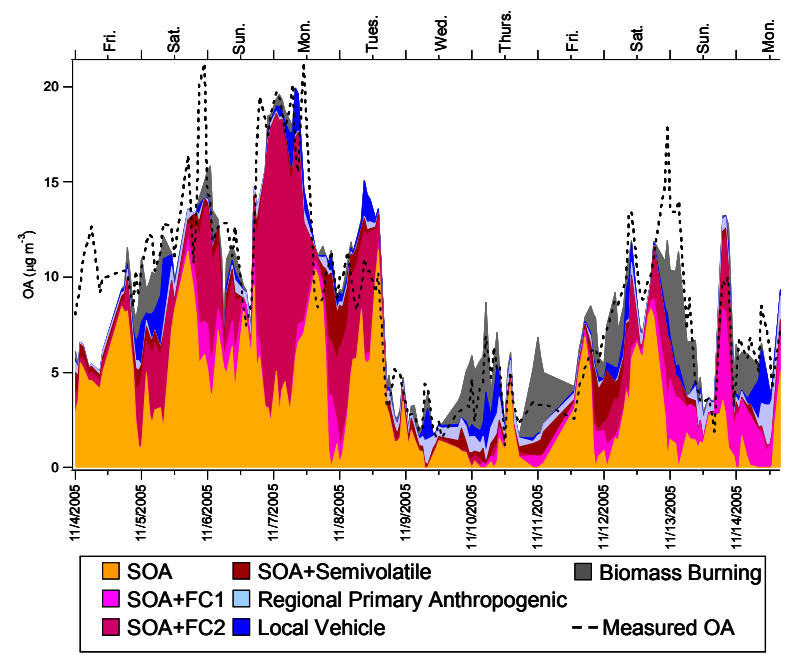

Fig. 9. Factor contributions to $\mathrm{PM}_{1}$ organic aerosol mass concentrations during the fall focus period (4 November-14 November). Dates are labeled at the beginning (midnight PST) of that day.

There is some overlap between species that are associated with SOA3 and the previously defined SOA factors. Phthalic acid, naphthofurandione, and xanthone contribute highly to both SOA2 and SOA3 factors, while dodecanoic acid, dihydro-5-dodecyl-2(3H)furanone, dihydro-5-tridecyl-2(3H)furanone, and octadecanone are highly correlated with both SOA1 and SOA3. However, there are several unique compounds in SOA3 including many oxygenated species containing ketone functional groups (dodecanedione, undecanedione, dioxaspirononanedione, dimethoxydiphenyl-ethanone, dihydro-5-ethyl-2(3H)furanone, and dihydro-5-decyl$2(3 \mathrm{H})$ furanone), and oxygenated compounds that contain phosphate and chlorine (chlorophosphatepropanol, bischloropropylphosphate, and chlorothalonil). The presence of several diketones in this factor may be further indication 


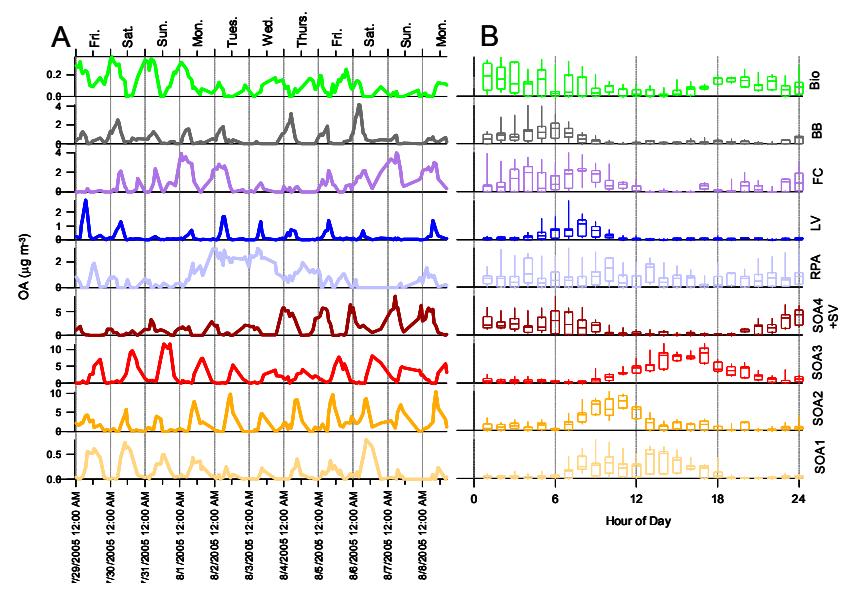

Fig. 10. (A) Individual PMF factor timelines over the summer focus period (29 July-8 August). (B) Diurnal averages for summer factors. Time is in PST (=local time-1hr during summer).

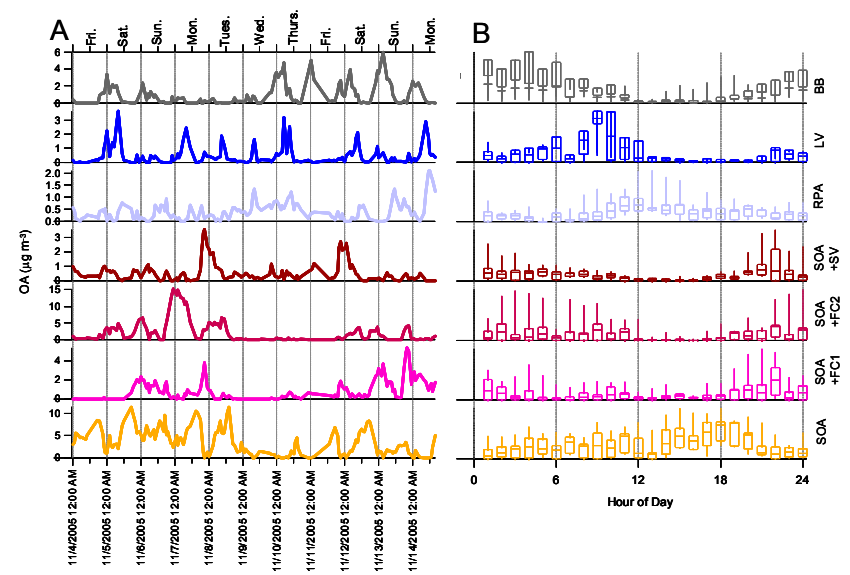

Fig. 11. (A) Individual PMF factor timelines over the fall focus period (4 November-14 November). (B) Diurnal averages for fall factors. Time is in PST (=local time during fall).

of the advanced photochemical age of this factor. Measurements obtained by other instrumentation that are highly correlated with SOA3 include air temperature, wind speed, odd oxygen, $\mathrm{O}_{3}$, pentanal, isoprene, methacrolein, and methyl vinyl ketone (Table 2), all of which are elevated during the daytime. Odd oxygen, a better indicator of gas-phase photooxidation products than $\mathrm{O}_{3}$, has a much higher correlation with SOA3 than with SOA1 or SOA2 $(r=0.84,0.39,0.24$, respectively), further suggesting a true distinction amongst these three SOA factors, with SOA3 being related to airmasses with the highest level of oxidation.

We define Factor 4 as a component containing SOA species along with oxygenated and nonoxygenated semivolatile species $(\mathrm{SOA} 4+\mathrm{SV})$. SOA species contributing to this factor include the ketones: methylfuranone,

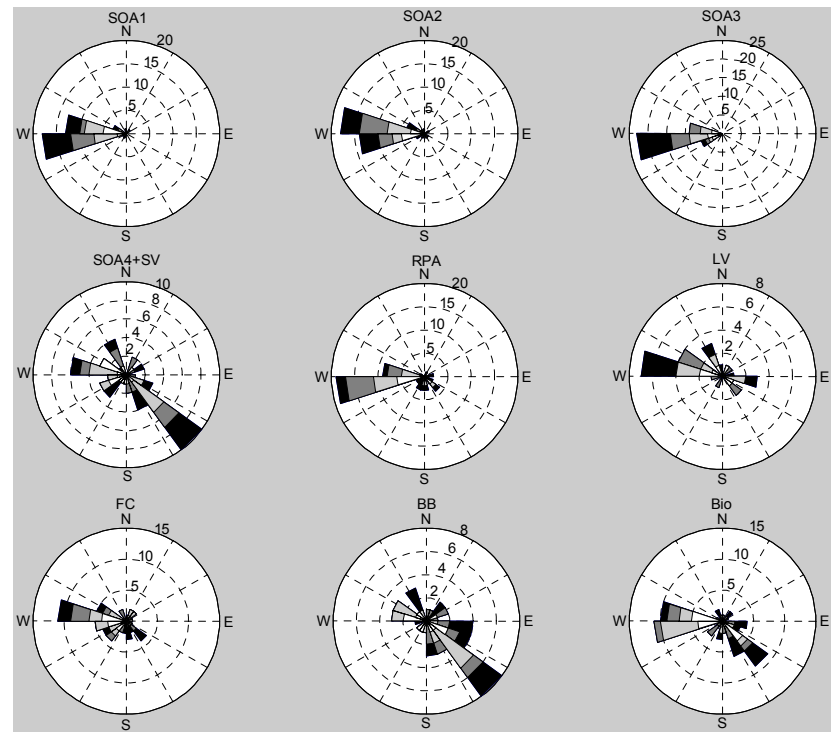

Fig. 12. Rose plots of the 9 summer PMF factors using only factor concentrations $>1$ standard deviation of mean factor concentration to emphasize dominant source directions. Frequency of observations are represented by the length of each wedge, and labeled by concentric rings. The shade of each wedge represents source concentrations in quartiles (dark = higher concentrations).

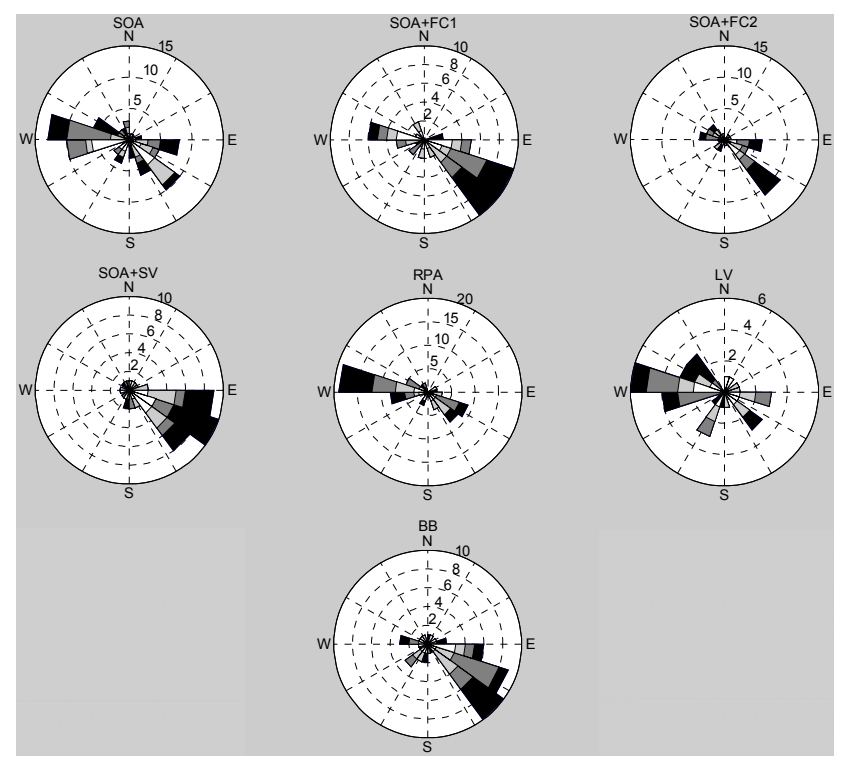

Fig. 13. Rose plots of the 7 fall PMF factors using only factor concentrations $>1$ standard deviation of mean factor concentrations to emphasize dominant source directions. Frequency of observations are represented by the length of each wedge, and labeled by concentric rings. The shade of each wedge represents source concentrations in quartiles (dark = higher concentrations).

pentylcyclohexanone, and dioxaspiroundecanone. Several other ketones not included in the PMF analysis are also highly correlated with this factor (Table S2). Many biogenic compounds contribute to this component, however, as 
explained below, are not considered to contribute all of the mass associated with this component. Examples of known biogenic compounds contributing to this factor are the terpenes: p-cymenene, $\alpha$-phellandrene, and $\delta$-3-carene. Other biogenic compounds not included in the analysis that display a high correlation to this factor include certain terpenes (i.e., $\gamma$-terpinene, and $\alpha$-terpinene) and oxygenated terpenes (i.e., pinonaldehyde, nopinone, $\alpha$-campholenal, and cuminic aldehyde). Many of these species are too volatile to exist in the aerosol phase according to partitioning theory (e.g. Donahue et al., 2006), and may again represent decomposition products in the GC-MS (Tobias et al., 2000) of larger biogenic species, or are present as gas-phase sample in the TAG system. The latter point is further explored by Williams et al. (2010).

This component is primarily associated with airflow from the southeast (Fig. 12) during the night. It is suspected that these biogenic compounds may have a contribution from the local agricultural test crops and botanical gardens found to the south of the University of California-Riverside campus. Unlike the factor that will be described in Factor 9, which contains lower volatility primary biogenic compounds, a majority of these biogenic compounds favor the gas-phase, and are likely condensing into the particle phase under wetter and cooler atmospheric conditions as is indicated by the anticorrelation between this factor and air temperature $(r=-0.52)$ and the positive correlation with relative humidity $(r=0.57)$. Potentially these species partition to the particle phase during the daytime as well, but are not observed due to the suspected emission region being downwind of the measurement site during daytime hours. This factor also includes compounds of unknown origin (methyloxaadamantane, methoxypyridine, pelletierine, and $\mathrm{N}-[(2-$ methoxyphenyl)methylene]-benzenamine). Some fraction of this component is composed of biogenic SOA, which even in urban regions has recently been indicated as an important source of SOA (Hodzic et al., 2009).

This factor contributes greater than $5 \mu \mathrm{g} \mathrm{m}^{-3}$ during several nighttime episodes (Fig. 10). However, even in the middle of the Amazon Basin, typically less than $1 \mu \mathrm{g} \mathrm{m}^{-3}$ of biogenic aerosol is generated (Chen et al., 2009). What is more likely occurring is SOA that was created during the daytime is still present (e.g. SOA3), and locally generated semivolatile tracer species are adsorbing onto the preexisting SOA aerosol. Therefore, while marker compounds suggest this is a separate nighttime component, it is more likely a transformation of the preexisting daytime aerosol via semivolatile phase partitioning of local emissions.

Further support of this hypothesis is seen by comparing the fraction of total OA that is derived through secondary processes between what was observed by AMS analysis and TAG analysis. The AMS is capable of determining mass concentrations of oxygenated organic aerosol (OOA) (Docherty et al., 2008). The diurnal profile over the summer focus period of the AMS-derived ratio of OOA to total
$\mathrm{OA}(\mathrm{OOA} / \mathrm{OA})$ is displayed in Fig. 14. Figure 14a shows the comparison between AMS OOA/OA ratio to TAG-derived SOA/OA, where SOA is defined here as the sum of SOA1, SOA2, and SOA3 PMF components. It is clear that there is additional nighttime OOA seen by the AMS. Figure 14b shows an improved correlation between AMS OOA/OA and TAG SOA/OA after including SOA4+SV to the sum of TAG-defined SOA components.

It has been suggested that phthalic acid could potentially be used as a single-species surrogate for the contribution of SOA to ambient aerosol (Fine et al., 2004a). Our results confirm that phthalic acid has the highest correlation with the sum of all 4 SOA components $(r=0.83)$. Of the compounds observed here, phthalic acid does appear to remain one of the best candidates for a single-species tracer of SOA in an urban environment. However, multiple sources/transformations of SOA, as observed here, are only derived using additional, less ubiquitous, secondary species. An exact interpretation of the differences between these SOA factors based on chemical composition alone is limited by the lack in unique source profiles for various secondary anthropogenic sources, combined with the potential for multiple formation pathways for secondary species.

During a study of air mass outflow from the Eastern United States, TAG defined two separate aged anthropogenic particle compositions, one highly associated with phthalic acid (US Outflow 2), and the other high associated with 1,6dioxaspiro[4,4]nonane-2,7-dione (US Outflow 1) (Williams et al., 2007). During the summer period in Riverside, CA, TAG has again observed a particle type with its largest single contribution coming from phthalic acid (SOA2), and another with its largest single contribution coming from 1,6dioxaspiro[4,4]nonane-2,7-dione (SOA3), arriving with air masses which are seemingly more photo chemically aged.

\subsubsection{Factors 5, 6: Regional Primary Anthropogenic (RPA) and Local Vehicle (LV)}

We define Factors 5 and 6, respectively, as regional primary anthropogenic (RPA) and local vehicle (LV) OA components. The diurnal profile of the LV component exhibits a distinct maximum in the early morning hours (06:0009:00 a.m. PST, 07:00-10:00 a.m. local time) corresponding with rush-hour traffic (Fig. 10). The diurnal profile of the RPA component is less pronounced and appears to have contributions throughout the day (discussed in more detail below in Sect. 3.5. Both components have high contributions when air arrives to the site from the west, but the LV component also contributes significantly when air arrives from the northwest and east (Fig. 12), indicating local influences.

The chemical composition of the RPA component is dominated by hydrocarbons, including alkanes, cyclohexanes, and PAHs (Fig. 6). The hydrocarbons observed in this component are typical of vehicular emissions (Schauer et al., 1999, 2002; Fraser et al., 1998; Rogge et al., 1993), 

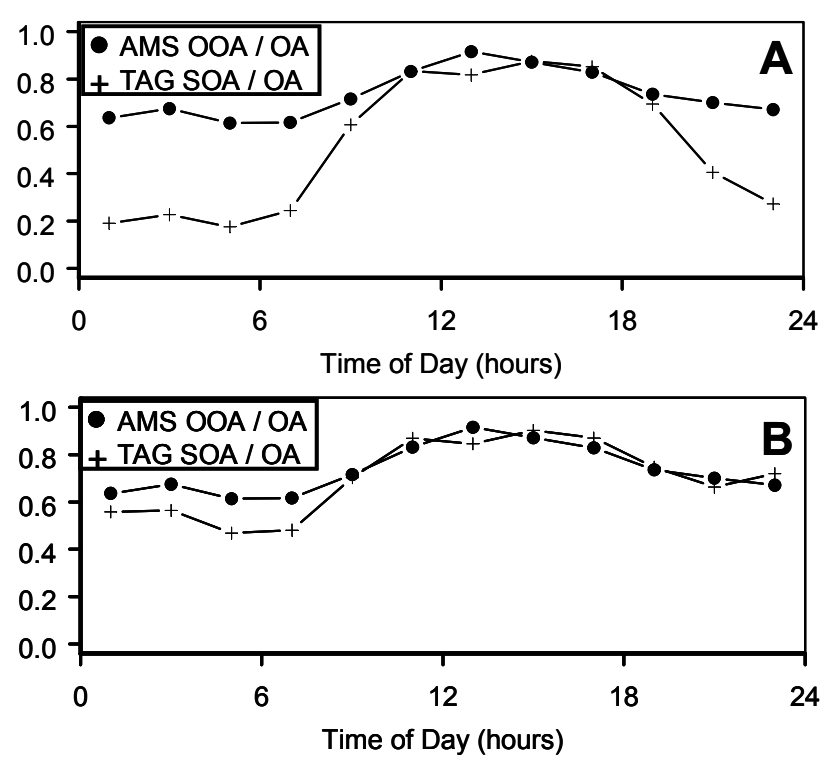

Fig. 14. (A) Average diurnal plots of AMS oxygenated organic aerosol (OOA) fraction of total OA (circles) and TAG secondary OA (SOA) fraction of total OA (plus symbols), with SOA defined as the sum of only SOA1, SOA2, and SOA3 PMF components. (B) Same as previous figure, except now including SOA4 + SV with the three previous TAG SOA components.

but do not include the hopanes and steranes typical of direct vehicle emissions. Similarly, the LV component has high contributions from alkanes, cyclohexanes, PAHs, and branched alkanes and PAHs, all of which are characteristic of vehicle emission profiles (Schauer et al., 1999, 2002; Fraser et al., 1998; Rogge et al., 1993) but, unlike RPA, has contributions from hopanes $(28$ nor- $17 \beta(\mathrm{H})$-hopane and $17-\alpha(\mathrm{H})-21 \beta(\mathrm{H})$-hopane).

The presence of hopanes in this component, but not in RPA may suggest that hopanes have a short atmospheric lifetime. This is consistent with recent chamber oxidation experiments (Weitkamp et al., 2008b; Lambe et al., 2009b). Acephenanthrylene, which has been shown to be significantly depleted in the South Coast Air Basin during the daytime compared to related PAHs (Arey et al., 1989) was also found in the LV component and not in the RPA component. It has been suggested that hopanes can have atmospheric lifetimes as short as 1 day during summer periods (Rudich et al., 2007). On average, it only takes approximately $10 \mathrm{~h}$ for air to traverse from Los Angeles to Riverside. While this transit time is shorter than the expected lifetime of hopanes, atmospheric oxidation and daytime dilution may cumulatively lower hopane levels below the TAG system's detection limits during RPA impact periods. Hopanes have been shown to favor the ultrafine aerosol mode (diameters $<180 \mathrm{~nm}$ ) in Riverside (Fine et al., 2004a). The TAG system does not collect a significant fraction of aerosols $<90 \mathrm{~nm}$ in diameter. A portion of the hopane mass is therefore not collected, but we as- sume the portion that is collected maintains the variability of the entire hopane mass. If this assumption was not true, then the TAG would likely collect hopanes even more efficiently as fresh emissions age and aerosol mass shifts from the ultrafine mode to the fine mode. This is not the case, as hopane concentrations measured by the TAG are only elevated in the morning, during heavy traffic and low atmospheric dilution. The presence of acephenanthrylene, and possibly hopanes, indicates that the LV component has not been subject to extensive atmospheric aging and, together with contributions from a variety of different wind directions, supports our assignment of this component as local vehicle emissions.

RPA does not display a regular daily maximum, but does have a midweek maximum, as could be expected from a regional vehicle source based on previously observed traffic patterns (Lough et al., 2006). It is likely this component arises from vehicular or other primary anthropogenic emissions from the western and central South Coast Air Basin.

RPA and LV components do not seem to represent a split between diesel and gasoline vehicle emissions. Since there is a higher emission ratio of elemental carbon (EC) from diesel fuel, EC is often used to differentiate diesel emissions from gasoline emissions. However, it appears that EC has some correlation with each of these factors. EC has clear morning maxima, indicating some local diesel emissions associated with the LV component (see Supplement, Fig. S7). However, EC persists throughout the day, unlike LV, and has an elevated background concentration during midweek similar to RPA. EC has a weekly Tuesday maximum $\left(1.51 \pm 0.44 \mu \mathrm{g} \mathrm{m}^{-3}\right)$ and a minimum on Sunday $\left(0.66 \pm 0.12 \mu \mathrm{g} \mathrm{m}^{-3}\right)$, as averaged across the entire 4-week summer study. This pattern is similar to what is observed in RPA, where there is a Tuesday maximum of $2.4 \mu \mathrm{g} \mathrm{m}^{-3}$, and a minimum on Saturday and Sunday of $0.2 \mu \mathrm{g} \mathrm{m}^{-3}$, during the focus period, however the amplitude of this variation is much larger for RPA (12 vs. 2.3), the reasons for which are unclear. LV does not display this trend. LV has a Friday maximum and a Sunday minimum. A combination of RPA and LV best explains the trends in EC. It is therefore more likely that the factor split between RPA and LV is more related to emission proximity and less to fuel type.

\subsubsection{Factor 7: Food Cooking (FC)}

We define Factor 7 as OA from food cooking (FC). This component is associated with many wind directions (Fig. 12) and lower wind speeds, indicating that this component originates from a more local set of sources. TAG compounds having highest contributions to this component are alkanoic acids (tetradecanoic acid, hexadecanoic acid, octadecanoic acid), alkylnitriles (hexadecanenitrile and octadecanenitrile), and nonanal, all molecular tracers for various types of food cooking (Rogge et al., 1991; Zheng et al., 2002; Zhao et al., 2007). Note that nonanal is too volatile to be present in the aerosol and could represent a decomposition product of the GC/MS 
analysis (Tobias et al., 2000), or as a reaction product of oleic acid (Reynolds et al., 2006). Regardless of its exact derivatization, it can still carry important source information. While many of these compounds can have secondary sources, this component is not elevated in the afternoon as would be expected of a secondary source (Fig. 10). Although there is likely as much, and potentially more, food cooking in the afternoon, the afternoon atmospheric concentrations are much lower due to increased dilution and oxidation as was seen with LV particles. All of these compounds have been identified in meat cooking source profiles, but most have also been identified in other food cooking source profiles. There is not enough information here to estimate emissions from specific food types (e.g., beef, pork, chicken, seed oils) and preparation methods (e.g., pan frying, charbroiling). We propose that this component represents an integration of OA from all food cooking operations.

Marker compounds often used specifically for meat cooking were detected (monostearin and monopalmitin), but their timelines are dominated by elevated concentrations on Friday and Saturday mornings (likely from a specific local source). This is the same day-of-week pattern previously observed in Los Angeles for these compounds (Lough et al., 2006). By removing these elevated events (all values more than 1 std. dev. above the mean) for monopalmitin and monostearin, there is an increased correlation between these compounds and the food cooking factor. Monopalmitin increases from a correlation $(r)$ of 0.08 up to 0.35 , and monostearin increases from 0.10 to 0.30 . Still, the food cooking factor does not fully capture local meat cooking aerosol. Monopalmitin and monostearin have the largest fraction of unexplained variance from the PMF analysis, with nearly half of their variability left unexplained. A separate "Meat Cooking" factor does eventually appear when solving for additional factors, but not until several of the larger sources have undergone further divisions. This is typical of PMF analyses where very small factors cannot be reliably retrieved among the noise and variations of the larger factors (Ulbrich et al., 2009).

Several biogenic compounds have high correlations to the identified food cooking aerosols. A few of them are salicylate compounds, which recently have been shown to have high emissions from desert plants, and mesquite in particular (Matsunaga et al., 2008). Another compound contributing to this factor is dimethoxydiphenyl-ethanone, which is structurally similar to compounds found in biomass smoke (Simoneit et al., 1993). This factor appears to build up over the weekend periods, with the two maxima both observed on Sundays. It is not possible to indicate how representative this is of a seasonal trend, given that the focus period only includes two weekends. Nonetheless, with the apparent elevated weekend concentrations and the nature of the correlated compounds' known sources, this additional information could suggest a portion of food cooking particles coming from weekend barbeques.

\subsubsection{Factor 8: Biomass Burning (BB)}

We define Factor 8 as biomass burning aerosol (BB). BB has highest contributions in air from the southeast, but also frequently in air transported from the west (Fig. 12). Compounds having large contributions to this factor include retene, vanillin, norabieta.4.8.11.13.tetraene, and norabietatetraene-mixture, all of which are known biomass burning marker compounds (Fine et al., 2001, 2004b; Rogge et al., 1998; Simoneit, 1989). Additional compounds with high correlations to this component are norabieta.3.8.11.13.tetraene, 19-norabieta.8.11.13.triene, abietatriene, galaxolide 1 , and precocene II, most of which are again known markers for biomass burning aerosol (Simoneit, 1989). Large alkanes and the parameter $C_{\text {wax }}$, a tracer for plant waxes, contribute significantly to this factor. There are a few nitrogen-containing compounds associated with this factor as well. Nitrogen-containing organics have not been reported in biomass burning aerosol source profiles, although hydrogen cyanide $(\mathrm{HCN})$ and acetonitrile $\left(\mathrm{CH}_{3} \mathrm{CN}\right)$ are well known gas-phase markers of biomass burning (Singh et al., 2003), thus it is reasonable to assume that there would be some $\mathrm{N}$-containing compounds in biomass burning aerosol. This factor his highly correlated with gas-phase measurements of acetonitrile, $\alpha$-pinene, and $\beta$-pinene (Table 2).

We note that the amount of the BB factor estimated from this study $\left(\sim 0.64 \mu \mathrm{g} \mathrm{m}^{-3}\right)$ is higher than that estimated from the CMB method applied to molecular markers measured in filters during SOAR-1 $\left(0.1 \mu \mathrm{g} \mathrm{m}^{-3}\right)$ (Docherty et al., 2008). This difference illustrates the uncertainties in current source apportionment methods, which may be larger for smaller sources which produce smaller tracer concentrations and are harder to disentangle from the variations of the larger sources (Ulbrich et al., 2009).

Biomass burning aerosol measured by ATOFMS as single particles rich in potassium correlates better with SOA2 than with this BB factor. This observation could indicate that some of the biomass burning aerosol from non-local sources has undergone photochemical processing, hence diminishing traditional primary organic marker compounds such as PAHs, but preserving inorganic tracers observed by ATOFMS (e.g., potassium). If this is the case, then this BB factor as defined by TAG compounds is representative of only the less-processed portion of the biomass burning plume. It is possible in principle that additional organic aerosol mass is originating from biomass burning sources, but is attributed to SOA2 after undergoing some degree of atmospheric aging. 


\subsubsection{Factor 9: Biogenic (Bio)}

We define Factor 9 as primary biogenics (Bio). This component has a very weak relation to wind direction and is observed as air moves to the site from almost every direction (Fig. 12), indicating local sources. Compounds with contributions to this factor include many biogenic compounds such as monoterpenes ( $\delta$-3carene, $\alpha$-phellandrene), homomenthylsalicylate, norabieta.4.8.11.13.tetraene, norabietatetraene-mixture, vanillin, and a portion of the parameter $C_{\mathrm{wax}}$ that is used as a marker for plant waxes. It is likely that this component is dominated by biogenic emissions. In addition to biogenic compounds, a tracer for pesticides (chlorothalonil), a compound commonly used for anti-scalding of fruit (diphenylamine), and a couple PAHs contribute to this factor. On average, very little mass is associated with this OA component.

\subsection{SOAR-2 (fall) PMF Results}

The $Q / Q_{\exp }$ value for a 7 factor solution with fpeak set to 0 (i.e., no rotation) is found to be 3.3, which is within a reasonable range according to the EPA PMF 1.1 User's Guide. Varying fpeak between \pm 2 in increments of 0.5 displays a minimum $Q / Q_{\exp }$ at fpeak $=0$, and using over 60 seeds (starting points) produces identical $Q / Q_{\exp }$ values for all solutions (see Supplement, Fig. S8). EPA PMF bootstrapping efforts confirm stable model results. Of 300 bootstraps, and of the resulting 2700 factors, only 32 factors (i.e., 1.2\%) did not match the factor profiles defined in the base case. Timeseries for all factors displayed a fit of $r^{2}=1$ between the 7factor solution from EPA PMF 1.1 and from the Igor-based PMF Evaluation Panel v2.02.

\subsubsection{Factors 1-4: SOA, SOA + Food Cooking1 (SOA + FC1), and SOA + Food Cooking2 $(\mathrm{SOA}+\mathrm{FC2}), \mathrm{SOA}+$ Semivolatile $(\mathrm{SOA}+\mathrm{SV})$}

Factor 1 contains many of the same molecular marker compounds as summertime SOA2 and SOA3 components, and will be referred to generally as SOA. The factor profiles and time series of fall SOA are shown in Figs. 7 and 9, respectively. Individual factor time series and average diurnal profiles are shown in Fig. 11. Compounds that display high contributions to this factor include several associated with summertime SOA2 including phthalic acid, 3-methylphthalic acid, and 4-methylphthalic acid and others associated with summertime SOA3 including dodecanedione, dioxaspirononanedione, dimethoxydiphenylethanone, and dihydro-5-ethyl-2(3H)furanone. This factor arrives to the site most frequently from the west (Fig. 13), as was seen during the summer for SOA2,3. The diurnal profile of this factor suggests that its highest impact on the site occurs between 02:00 p.m.-08:00 p.m. PST (same as local time in fall) (Fig. 11), resembling SOA3 from the summer, but also contributes significant aerosol mass during the morning hours as SOA2 did during the summer. This SOA factor has the highest correlation with $\mathrm{O}_{\mathrm{x}}$ during the fall (Table 2).

Factor 2 contains many of the same molecular marker compounds as summertime SOA1, SOA2, and FC, and will be referred to as SOA plus food cooking type 1 $(\mathrm{SOA}+\mathrm{FC} 1)$. Compounds that have high contributions to this factor include several associated with summertime FC aerosol (tetradecanoic acid, hexadecanoic acid, octadecanoic acid, and nonanal), and some associated with summertime SOA1 (nitrophenylbenzenamine) and summertime SOA2 (4-nitrophenol).

All amine-containing compounds contribute significantly to $\mathrm{SOA}+\mathrm{FC} 1$ (Fig. 7). Additionally, there is a high correlation between the SOA + FC1 component and the ATOFMS submicron Amine cluster (Table 2). Stable aminium salts could be formed from the presence of both amines and organic acids in SOA + FC1 aerosol, and could explain the presence of high volatility amines and organic acids in the particle phase. For example, 4-methoxy-pyridine has an estimated vapor pressure of $\sim 3$ torr (EPA, 2008) and heptanoic acid has an estimated vapor pressure of $\sim 0.1$ torr (EPA, 2008). Both are far too volatile to be in the particle phase, but have a measureable mass fraction present in the particle phase according to TAG collection and analysis. Aminium salts have been observed as contributing to nanoparticle growth in the atmosphere and are detected through thermal desorption techniques as individual low molecular weight amines and acids (Smith et al., 2010). As mentioned earlier, these low molecular weight compounds detected by TAG could also be thermal decomposition products of larger molecular weight organic species (Tobias et al., 2000), or oligomers (Denkenberger et al., 2007).

Factor 3 contains many of the same molecular marker compounds as summertime SOA3 and FC, and will be referred to as SOA plus food cooking type 2 $(\mathrm{SOA}+\mathrm{FC} 2)$. Compounds that contribute to this factor include several associated with summertime FC aerosol (hexadecanenitrile and octadecanenitrile). Other compounds contributing to this factor are also associated with summertime SOA3 (naphthofurandione, undecanedione, xanthone, dihydro-5-ethyl-2(3H)furanone, and dihydro-5dodecyl-2(3H)furanone). Many other measurements were highly correlated with SOA + FC2, including total OA, many ATOFMS clusters, VOCs, and OVOCs.

Other TAG compounds not used in the analysis display high correlations with the two SOA + FC factors, including many acids, ketones, and aldehydes (Table S2). These two factors appear to be an accumulation of various primary and secondary compounds. TAG data suggest the primary compounds originate from food cooking operations. It is not certain what ties these seemingly unrelated processes, but it is probable that aged particles high in SOA are mixing with more freshly-emitted food cooking particles. The difficulty of separating components with PMF2 during 
periods of lower photochemical activity has been previously reported for AMS spectra, where the difficulty of separating the mixed factors was due to the larger importance of meteorological transport (Lanz et al., 2008). In that study, an improved separation was possible with the use of a more advanced linear model implemented with the multilinear engine (ME-2), which is of interest but outside of the scope of the present study.

Both SOA + FC components have highest concentrations in air arriving at the site from the southeast, and less frequently from the west according to measurements made at the SOAR site (Fig. 13). Backward trajectories, performed using HYSPLIT (Draxler and Rolph, 2010; Rolph, 2010) and run at 3 elevations $(10,50,100 \mathrm{~m})$ for a $36-\mathrm{h}$ duration, suggest these air-masses were relatively stagnant during the highest concentrations of SOA + FC2 on 7 November, and on 8 November, also high in SOA + FC2, air masses had traversed San Diego and moved north to Riverside (see Supplemen, Fig. S9). Backward trajectories for the three largest SOA + FC1 events $(6,13,14$ November) suggest that these air masses came from the San Joaquin Valley, a highly agricultural region. Both SOA + FC components appear in discrete events, not as a regular diurnal cycle as is observed with the SOA component (Fig. 11). The events are highest during the night and occur between Saturdays and Mondays as was observed for the summer FC factor. It may be possible that, as was observed for SOA4 + SV during the summer, these SOA + FC factors are dominated by SOA which was created during the daytime, and locally generated FC tracer species are adsorbing onto, or mixing with, the preexisting SOA aerosol.

Factor 4 contains many of the same molecular marker compounds as summertime SOA4 + SV aerosol, and the designation of this component is retained. Many primary and secondary biogenic compounds contribute to this factor. Examples of known biogenic compounds are the terpenes: $\alpha$-phellandrene, $\gamma$-terpinene, $\delta$-3-carene, and $\beta$-selinene. Oxygenated biogenic compounds such as pinonaldehyde, cuminic aldehyde, and methyl chavicol also contribute to this factor. As discussed above many of these compounds are too volatile to be in the aerosol phase and may represent decomposition products in the GC-MS (Tobias et al., 2000) of larger biogenic species, or are present as gas-phase sample in the TAG system. The latter point is further explored by Williams et al. (2010). Included in this SOA4 + SV factor are the same compounds of unknown origin that were associated with this factor during the summer period (methyloxaadamantane, methoxypyridine, pentylcyclohexanone, and $\mathrm{N}$-[(2-methoxyphenyl)methylene]-benzenamine).

This component was observed in air arriving at the site from the east-southeast (Fig. 13) during the night. It is again suspected that some fraction of these biogenic compounds are from local agricultural test crops and botanical gardens found within the University of California-Riverside campus. As during the summer, there is an anticorrelation between this factor and air temperature $(r=-0.44)$ and a positive correlation with relative humidity $(r=0.48)$. As was hypothesized of this factor during the summer, it is more likely that SOA which was created during the daytime is still present, and locally generated semivolatile tracer species are adsorbing onto the preexisting SOA aerosol, and therefore this factor may be dominated by preexisting SOA material.

\subsubsection{Factor 5: RPA}

Factor 5 contains many of the same molecular marker compounds as summertime RPA, and we, therefore, retain the designation for this factor. This component is most frequently observed in air arriving at the site from the west, with less frequent contributions in air from the southeast as well (Fig. 13). The chemical composition of this component is dominated by hydrocarbons, including several straight and branched alkanes, cyclohexanes, and branched PAHs (Fig. 7) along with a few oxygenated species. Similar to summer RPA, the particulate hydrocarbons observed in this aerosol type are typical of vehicular emissions (Schauer et al., 1999, 2002; Fraser et al., 1998; Rogge et al., 1993), but, as previously observed, does not include hopanes and steranes often characteristic of direct vehicle emissions. While RPA in the fall increases midweek as was observed in the summer, fall RPA also has a slight diurnal trend with elevated concentrations during the daytime (Fig. 11). Other parameters with high correlation to RPA include air temperature, visible light, and wind speed, again indicating daytime transport of this component from a regional source, and potentially indicates that evaporative sources may contribute to this factor, another potential explanation for low volatility hopanes not being

\subsubsection{Factor 6: LV}

Factor 6 contains many of the same molecular marker compounds as summertime LV aerosol, and again we retain the designation of this factor. This component has large contributions from hopanes (norhopane and hopane), several cyclohexanes, PAHs, and branched PAHs, all of which are characteristic of vehicle emission (Schauer et al., 1999, 2002; Fraser et al., 1998; Rogge et al., 1993). LV is observed most frequently in air arriving at the site from the west (Fig. 13). The diurnal trend of this factor is similar as was observed in the summer, with highest concentrations occuring during the morning hours of 06:00 a.m.-12:00 p.m. PST (same as local time) (Fig. 11). CO, o-xylene, and small alkanes, alkenes, and alkynes, are also correlated with this factor, all of which have known vehicular sources (Millet et al., 2005, 2006).

\subsubsection{Factor 7: BB}

Factor 7 contains many of the same molecular marker compounds as summertime BB aerosol, and our designation is retained. Biomass burning aerosol is observed in air arriving 
at the site almost exclusively from the southeast (Fig. 13). Compounds that contribute significantly to this factor include norabieta.4.8.11.13.tetraene, norabietatetraene-mixture, 8isopropyl-1,3-dimethylphenanthrene, retene, dehydroabietic acid-methyl ester, and 7-oxodehydroabietic acid-methyl ester, all known biomass burning marker compounds (Fine et al., 2001, 2004b; Rogge et al., 1998; Simoneit, 1989). Additional compounds with high correlations to this component are 19-norabieta-3,8,11,13-tetraene, 19-norabieta-8,11,13triene, dehydroabietin, $\alpha$-campholenal, lily aldehyde, and pinonaldehyde, many of which are potential markers for biomass burning aerosol. BB aerosol during the fall has highest concentrations during the night, not necessarily indicating more burning occurred at night than during the day, but BB aerosol concentrations may simply increase at night due to trapping of fresh emissions in the stable nighttime surface boundary layer.

\subsection{Residuals}

The residual variability from summer and fall PMF analyses have both positive and negative values, meaning that at times the solution over-explains the variability and other times the solution under-explains the variability. The net residual term was slightly positive for both sampling periods, with an average value of $3 \pm 4 \%$ of the total variance during the summer and more variable in the fall, with an average value of $1 \pm 11 \%$ of the total variance (Fig. S10). The higher variance of the residual term in the fall could partially be due to differences in local sources between the SOAR site and the Rubidoux site, which was used to interpolate missing OA data from the SOAR site. Individual compounds that remained nearly $50 \%$ under-explained (i.e., the reconstructed signal from the chosen PMF solution is only half of the measured signal) during the summer included monopalmitin, monostearin, methylnitrophenol, and methyldiamantane, where octadecanoic acid was the most over-explained parameter by about $35 \%$ (Fig. S11a). In the fall, monopalmitin and oleic acid were $\sim 35 \%$ under-explained and nitrophenylbenzenamine was $35 \%$ over-explained (Fig. S11b).

Residual values were not included in the multivariate fit of PMF components to total OA. Differences between measured $\mathrm{OA}$ and $\mathrm{OA}$ from the sum of fitted components is displayed in Fig. 8 (summer) and Fig. 9 (fall), where the dashed line represents measured OA and the sum of all factors represents fitted OA mass concentrations. Average diurnal differences are displayed in Fig. 15 (summer) and Fig. 16 (fall).

\subsection{Source contributions to OA mass}

Cumulative mass concentration timelines for summer (fall) OA factors are shown in Fig. 8 (Fig. 9), and individual timelines are shown in Fig. 10a (Fig. 11a). Here, it is clear that there are significant differences between summer and fall OA contributions, with repeatable daily variations of each factor in the summertime, and less repeatable "events" dominating during the fall, which is consistent with the much higher meteorological variability during the latter campaign.

Table 3 reports the average mass concentration contribution from each of the major PMF factors over each focus period. The reported error incorporates the fitting error associated with fitting our PMF components to total OA as previously described, as well as propagated TAG and AMS measurement errors. The summer period appears to be dominated by SOA, where the sum of all 4 SOA-associated factors averages $6.4 \mu \mathrm{g} \mathrm{m}^{-3}$ of OA, or $68.5 \%$ of total OA. The sum of all primary-associated anthropogenic OA factors (RPA, LV, and FC) averages $2.1 \mathrm{\mu g} \mathrm{m}^{-3}$ of OA, or $22.3 \%$ of total OA. $\mathrm{BB}$ aerosol contributes an average $6.8 \%$ of total OA. Primary biogenic (Bio) aerosol contributes an average of $1.2 \%$, and the remaining organic mass contributes only $1.1 \%$ to total summer OA on average. Docherty et al. (2008) recently reported an intercomparison of five commonly used methods to estimate the SOA/OA fraction during SOAR-1, and reported $75 \%$ (range $68-84 \%$ ) as the average of the methods. The results of the present study are on the lower end of the five methods reported in that study.

The fall period is dominated by SOA and $\mathrm{SOA}+\mathrm{FC}$ factors. The sum of SOA, SOA $+\mathrm{FC} 1, \mathrm{SOA}+\mathrm{FC} 2$, and $\mathrm{SOA}+\mathrm{SV}$ contributes an average of $6.9 \mu \mathrm{g} \mathrm{m}^{-3}$ of $\mathrm{OA}$, or $77.9 \%$ of total OA. These factors do however include markers for both SOA and primary emissions. Other primaryassociated anthropogenic factors (RPA, LV) contribute an additional $10.1 \%$ of the OA mass. BB aerosol contributes a significant amount of OA mass during the fall (10.8\%), leaving a remaining $1.2 \%$ of total $\mathrm{OA}$ mass unexplained by these factors, a similar amount to the remaining OA mass during the summer study.

Here, we compare our observations of source contributions to total OA, or organic matter $(\mathrm{OM})$, to previous studies which have typically reported source contributions to total OC. Recent measurements of the OM/OC ratio (Turpin and Lim, 2001; Aiken et al., 2007, 2008; DeCarlo et al., 2008; Dunlea et al., 2008) report that SOA has a significantly higher OM/OC $(\sim 1.7-2.4)$ than urban POA $(\sim 1.3)$ and fresh biomass burning aerosol ( 1.6-1.7). Since we will be comparing time averaged results that include sources of both primary and secondary material, we use our separation of summertime SOA $(68.5 \%$, includes SOA1,2,3, SOA4 + SV with an estimated average $\mathrm{OM} / \mathrm{OC}$ value $=2.05$ ), $\mathrm{POA}$ (23.5\%, includes RPA, LV, FC, and Bio), BB (6.8\%, with an estimated average $\mathrm{OM} / \mathrm{OC}$ value $=1.65)$, and remaining $\mathrm{OA}(1.2 \%$, with an estimated $\mathrm{OM} / \mathrm{OC}$ value $=1.67$ averaged from all 3 categories) to estimate a total average $\mathrm{OM} / \mathrm{OC}$ ratio $\quad(=685 \times 2.05+235 \times 1.3+068 \times 1.65+012 \times 1.67)$ equal to 1.84 . Our comparisons to previous work will be primarily focused on the summer period (SOAR-1).

Almost all previous studies have concluded that primary sources dominate all $\mathrm{PM}_{2.5} \mathrm{OA}$ in the inland region of 
the South Coast Air Basin, with the exception of short periods during intense photochemical episodes with more than $200 \mathrm{ppb} \mathrm{O}_{3}$ (Docherty et al., 2008). Thus our study is consistent with the recent results of Docherty et al. in the dominance of SOA-associated factors that account for $\sim 69 \%$ of OA in Riverside during SOAR-1.

Sawant et al. (2004) estimate that only a small amount of the concentrations resulting from primary emissions of gasoline and diesel particles in Mira Loma, CA are from local sources, a finding that is supported by our PMF results. Applying a chemical mass balance model to characteristic OC/EC profiles for various emission types, $\mathrm{Na}$ et al. (2004) estimated that an average of approximately $35 \%$ of the OC comes from gasoline and diesel primary emissions. Our findings show a fraction of total OA on the order of $11 \%$ during both seasons coming from primary vehicle emissions. Assuming $\mathrm{OM} / \mathrm{OC}=1.3$ for this primary fraction, and applying our estimated $\mathrm{OM} / \mathrm{OC}$ ratio (1.84) for the remaining aerosol fraction, then our findings would estimate that primary vehicle emissions contribute approximately $16 \%$ of the OC. It is possible that we find a smaller vehicular contribution due to the incorporation, within the PMF analysis, of several additional sources not accounted for by some previous studies (e.g., biogenic emissions, biomass burning, food cooking), and due to our inclusion of a variety of oxygenated species not analyzed in previous studies. The sum of reduced OA species, which are taken as a surrogate of POA and likely include vehicle emissions, food cooking, etc., contribute $36 \%$ of the OA in Pittsburgh (Ulbrich et al., 2009), still higher than our combined POA contribution of $23.5 \%$ to total OA in Riverside. In a recent urban air study, vehicular emissions were determined to contribute an annual average of $14 \%$ of total OC concentrations in Toronto and Vancouver, Canada (Brook et al., 2007). This result is more similar to our findings of $16 \%$, although there may be other differences between the airsheds in both studies. It has also been shown recently that atmospheric reactions may react away some of the primary vehicle emission tracers, which may lead to an underestimation of vehicle emissions OA when using tracers (Weitkamp et al., 2008b). However this effect is likely smaller when more tracers are used such as in the present analysis.

Hildemann et al. (1989) calculated through emission inventories that up to $20 \%$ of total OC in the South Coast Air Basin can be composed of aerosol derived from food cooking operations. This estimate is above our derived contributions from food cooking operations, at least during the summertime. It has recently been shown in the Pittsburgh region that food cooking operations can contribute an average of $10 \%$ of the total OC (Robinson et al., 2006) which is closer to the summertime food cooking contributions observed here. It should be noted that recent studies have questioned the use of some food cooking molecular marker compounds in the ambient atmosphere due to potential contributions from soilrelated sources (Jaeckels et al., 2007) and atmospheric reac- tions (Weitkamp et al., 2008a), although those marker compounds in question are not the only food cooking markers used in our PMF analyses.

Biomass burning aerosol in this region is variable from season to season and from year to year. Periods of intense fires in Southern CA can lead to a dominance of BB over other OA sources over periods of weeks (Phuleria et al., 2005), while the influence during other periods is much smaller (Docherty et al., 2008). During our selected focus periods, biomass burning aerosol contributed greater mass concentrations and a larger fraction of total OA during the fall in comparison to the summer.

To our knowledge, there has not been a previous measurement of biogenic aerosol mass contribution in Riverside, CA. However, the presence of a primary biogenic factor during the summer and none during the fall is consistent with seasonal photosynthesis and biogenic VOC emission patterns.

\subsection{Average diurnal variations in OA composition}

Diurnal trends as averaged over the 11-day focus period and with 2-h time resolution, are shown using time-of-day pie charts in Fig. 15 (Fig. 16) for summer (fall), and as continuous timelines in Fig. 10b (Fig. 11b). Total OA mass concentrations fluctuate between $5.3-13 \mu \mathrm{g} \mathrm{m}^{-3}$ during an average summer day in Riverside (Fig. 15). The fraction of fine particle mass (AMS species + EC) that is composed of organics during the summer varies throughout the day, with a maximum (52\%) in the afternoon between 16:00-18:00 PST, a minimum in the morning (37\%) between 08:00-10:00 PST, and a total daily average of $43 \pm 5 \%$. Fall diurnal trends, with 2-h time resolution, show total OA mass concentrations fluctuate between $5.7-10.3 \mu \mathrm{g} \mathrm{m}^{-3}$ (Fig. 16). The fraction of fine particle mass that is composed of organics during the fall also varies throughout the day, with a maximum (43\%) at night between 02:00-04:00 PST, a minimum (29\%) in the afternoon between 16:00-18:00 PST, and a total daily average of $35 \pm 4 \%$. The fraction of fine particle mass that is composed of organics is highest in the afternoon during the summer and lowest during the afternoon in the fall. This again reflects the large influence of afternoon SOA during the summer. Because EC was not measured during the fall, the same fraction of total $\mathrm{PM}_{2.5}$ mass (measured by BAM) composed of EC (measured by OC/EC monitor) during the summer (i.e., 4\%) was used to calculate an approximate fall EC concentration. This is the same fraction of total $\mathrm{PM}_{2.5}$ that $\mathrm{EC}$ has been observed to contribute in this region during the fall in previous years (Sawant et al., 2004).

Figures $10 \mathrm{~b}$ and 15 show that summer local primary components (LV, FC, Bio) tend to reach a maximum during the morning hours, while SOA components (SOA1, SOA2, SOA3) are elevated later in the day, other components $(\mathrm{SOA} 4+\mathrm{SV}, \mathrm{BB})$ are at their highest concentrations during the night, and the regional factor RPA does not have a clear diurnal trend. The RPA component is elevated during 


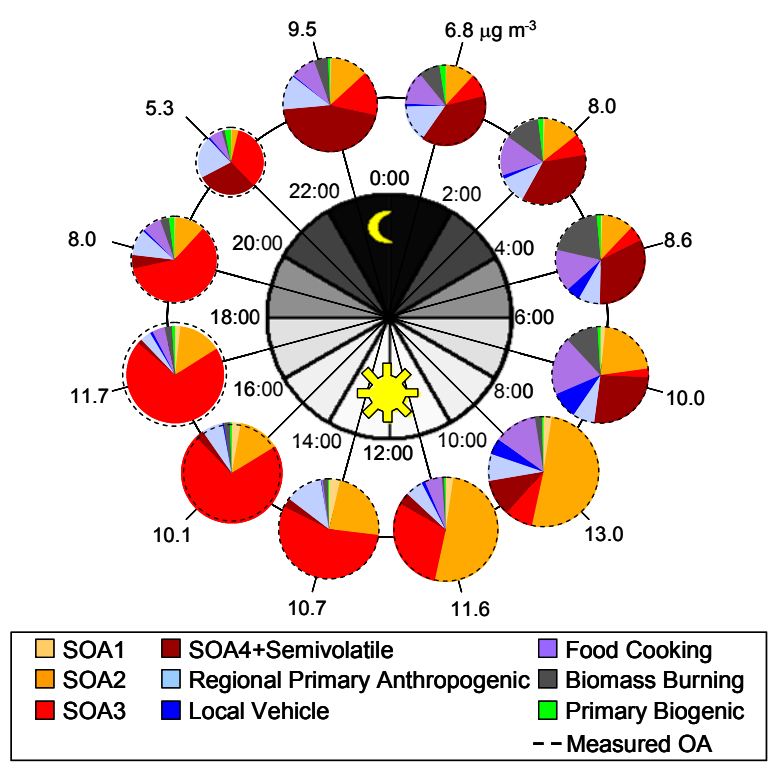

Fig. 15. Average diurnal concentrations of TAG-derived PMF factors over the summer focus period. $\mathrm{PM}_{1}$ organic aerosol mass concentrations labeled outside of pie chart ring, and time of day labeled inside of pie chart ring.

midweek and likely has high concentrations during midweek afternoons due to transport from regional primary sources and high nighttime midweek concentrations due to decreased dillution in a shallow atmospheric boundary layer.

There are distinct differences in diurnal variability, as well as chemical composition, among the 3 daytime summer SOA components. SOA1 appears with the morning sunlight (07:00 PST) and remains elevated until late afternoon (18:00 PST). SOA2 also appears with the morning sunlight (07:00 PST), typically reaches a maximum just before noon (10:00-12:00 PST), and has significantly lower concentrations by early afternoon (14:00 PST). However, SOA3 does not appear until later in the morning (09:00 PST), reaches a maximum later in the afternoon (14:00-16:00), and slowly decreases in the evening (22:00 PST), interestingly, at the same time SOA4 + SV begins to increase. SOA3, which contains diketones and has the highest correlation with odd oxygen, is clearly representative of a different atmospheric age distribution than the other SOA components, and based on wind speeds and wind directions, is likely more representative of a transported, aged, regional SOA. Since SOA1 and SOA2 still have measureable concentrations later in the afternoon, a fraction of SOA1 and SOA2 may also be due to regional SOA in addition to SOA from local sources. SOA $4+$ SV has been discussed previously, and is likely the result of local semivolatile species mixing and/or adsorbing onto SOA3 that remains during the evening and night. The sum of the four summertime SOA factors has an estimated average afternoon concentration of $9.4 \mu \mathrm{g} \mathrm{m}^{-3}$, and accounts for $88 \pm 2 \%$ of the OA mass during the afternoon

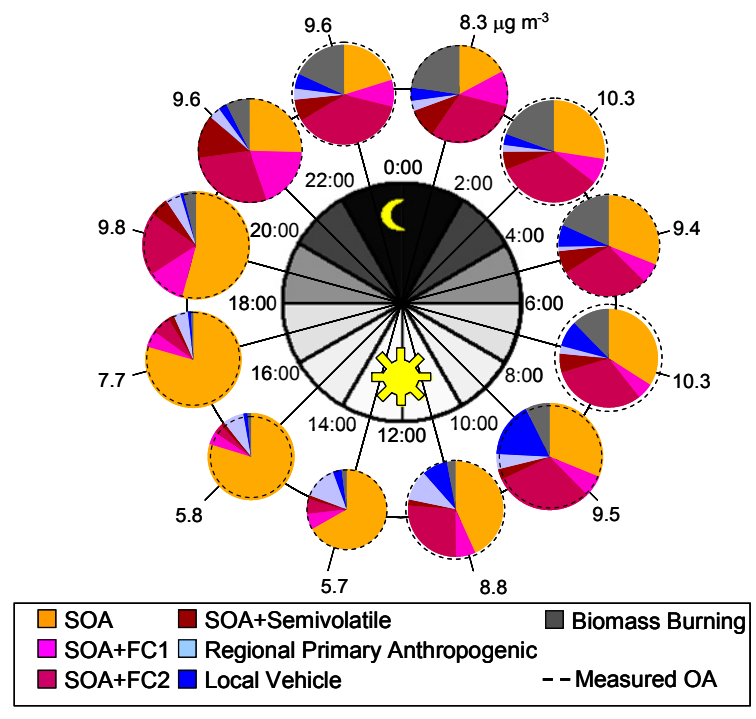

Fig. 16. Average diurnal concentrations of TAG-derived PMF factors over the fall focus period. $\mathrm{PM}_{1}$ organic aerosol mass concentrations labeled outside of pie chart ring, and time of day labeled inside of pie chart ring.

hours (12:00-18:00 PST), which is consistent with previous estimates using five different SOA/OA estimation methods (Docherty et al., 2008).

In the fall, secondary sources of $\mathrm{OA}(\mathrm{SOA}, \mathrm{SOA}+\mathrm{FC} 1$, $\mathrm{SOA}+\mathrm{FC} 2, \mathrm{SOA}+\mathrm{SV}$ ) are more difficult to separate with PMF and appear more mixed than summer SOA sources. In Figs. $11 \mathrm{~b}$ and 16 it is apparent that SOA and RPA contribute significantly to midday OA at the site. LV aerosol has a maximum in the morning. BB and SOA $+\mathrm{SV}$ both have a maximum contribution to $\mathrm{OA}$ mass during the night, as was also observed in the summer.

\section{Conclusions and implications}

The first ever hourly measurements of speciated organic aerosol in an urban region were successfully obtained. Sampling was completed at Riverside, CA, over the summer and fall of 2005. Approximately 300 different organic compounds ranging from nonpolar hydrocarbons to polar acids, aldehydes, and ketones were analyzed in detail over 11-day periods for each season.

Select compounds were used to complete a PMF analysis to identify the major factors contributing to fine-mode OA. Similar contributing factors were discovered over both seasons, including factors associated with local vehicle emissions, regional primary anthropogenics, several types of SOA, food cooking operations, particle-phase biogenics, semivolatile anthropogenics and biogenics, and biomass burning aerosol. This analysis offers a more detailed view of diurnal contributions to organic aerosol mass from major components/sources than has been reported before. Only 
with the high time resolution TAG measurements of speciated organic marker compounds is it possible to view organic aerosol contributions at such high time frequency. One uncertainty in our approach arises from the method of apportioning total $\mathrm{OA}$ to the factors resulting from the tracer PMF analysis.

Summertime organic aerosol factors had very regular diurnal contributions, with SOA-associated factors contributing as much as $88 \pm 2 \%$ of fine OA mass during the afternoon $(68.5 \%$ when averaged diurnally), which is within the range of SOA/OA fractions reported by five other methods during SOAR-1 (Docherty et al., 2008). There appears to be contributions to OA from biogenics and other local anthropogenic emissions during the night and morning. Regional primary anthropogenic particles plus local vehicle particles contributed approximately $11 \%$ of OA over both seasons. While primary vehicle factors, local and regional, account for a relatively small fraction of the OA during both seasons, volatile vehicle emissions are photochemically processed in the atmosphere and are likely responsible for creating large amounts of observed SOA.

A substantial amount of SOA was also observed in the fall, however three of the SOA-containing PMF factors were mixed with either food cooking tracers or tracers of biogenic and anthropogenic primary emissions, making it impossible to clearly estimate an SOA/OA ratio. There was a primary biogenic factor that was observed in the summer, but not in the fall. Conversely, the biomass burning factor was found to contribute a larger fraction of total OA during the fall than compared to summer.

An important finding of this study was the presence of several separate SOA factors, which have also been reported with other techniques such as PMF of AMS spectra (Lanz et al., 2007; Ulbrich et al., 2009; Ng et al., 2009; Jimenez et al., 2009) and CMB with improved secondary tracers (Kleindienst et al., 2007). An interpretation of the differences among these SOA types, based on chemical composition alone, is limited by a lack of source profiles for secondary sources. This highlights the need for further SOA source profile studies. However, since many of the oxygenated compounds present in SOA are products of multiple reaction pathways, there may always be a limitation to defining SOA sources based on source profiles alone. Future studies should especially target unique oxygenated compounds that have one dominant source. Worth highlighting is our observation here that one summertime SOA component (SOA2) has large contributions from phthalic acid and other mono-acids and mono-ketones, where another SOA component (SOA3) has large contributions from 1,6-dioxaspiro[4,4]nonane-2,7dione and other di-ketones, and whose diurnal profile and high correlation with $\mathrm{O}_{\mathrm{x}}$ suggests further atmospheric aging compared to SOA2. These two factors are similar to particle types observed in outflow from the Eastern United States, where TAG analysis defined two separate aged anthropogenic particle compositions, one highly associated with phthalic acid (U.S. Outflow 2), and the other high associated with 1,6-dioxaspiro[4,4]nonane-2,7-dione (US Outflow 1) (Williams et al., 2007).

The majority of the aerosol mass arriving in Riverside, on the eastern edge of the South Coast Air Basin, is secondary in nature. This indicates that by the time air masses escape the basin, much of the atmospheric organic matter originating in the South Coast Air Basin has undergone some degree of chemical aging, and additional SOA has been created from gas-to-particle photochemical processes. This aging increases particle hygroscopicity (Kanakidou et al., 2005), and in turn increases the aerosol's ability to alter cloud formation and precipitation (Ramanathan et al., 2001). Additionally, high concentrations of SOA and $\mathrm{O}_{3}$ observed during the summer causes concern for the health of those residing within and downwind of the L. A. region (Dockery et al., 1993; Folinsbee, 1992; Schwartz et al., 1996, 2001; Jang et al., 2006).

\section{Supplementary material related to this article is available online at: http://www.atmos-chem-phys.net/10/11577/2010/ acp-10-11577-2010-supplement.pdf.}

Acknowledgements. This work was supported by the California Air Resources Board (CARB) award number 03-324. We would like to thank Nehzat Motallebi of CARB for her support throughout the contract period, and CARB for providing BAM measurements. KSD and JLJ acknowledge support from EPA (RD-83216101-0), NSF (ATM 0449815 and 0919189), and NOAA (NA08OAR4310565). This manuscript has not been reviewed by funding agencies and no endorsement should be inferred. We thank Paul Ziemann of UC-Riverside for logistical support during the SOAR studies. We would also like to thank Megan McKay, Angela Miller, and Dylan Millet for their assistance in operating the Goldstein Mobile Lab. We thank David Snyder and Jamie Schauer of the University of Wisconsin-Madison for use of their OC/EC data collected during SOAR. We thank Kim Prather, Laura Shields, and Sharon Qin of UC-San Diego for use of their ATOFMS data collected during SOAR. The authors gratefully acknowledge the NOAA Air Resources Laboratory (ARL) for the provision of the HYSPLIT transport and dispersion model and READY website (http://www.arl.noaa.gov/ready.php) used in this publication. Finally, we thank the anonymous reviewers of this manuscript for their insightful comments and recommendations.

Edited by: M. C. Facchini

\section{References}

Aiken, A. C., DeCarlo, P. F., and Jimenez, J. L.: Elemental analysis of organic species with electron ionization highresolution mass spectrometry, Anal. Chem., 79, 8350-8358, doi:10.1021/ac071150w, 2007.

Aiken, A. C., DeCarlo, P. F., Kroll, J. H., Worsnop, D. R., Huffman, J. A., Docherty, K. S., Ulbrich, I. M., Mohr, C., Kimmel, J. 
R., Sueper, D., Sun, Y., Zhang, Q., Trimborn, A., Northway, M., Ziemann, P. J., Canagaratna, M. R., Onasch, T. B., Alfarra, M. R., Prevot, A. H., Dommen, J., Duplissy, J., Metzger, A., Baltensperger, U., and Jimenez, J. L.: O/C and OM/OC ratios of primary, secondary, and ambient organic aerosols with high resolution time-of-flight aerosol mass spectrometry, Environ. Sci. Technol., 42, 4478-4485, doi:10.1021/es703009q, 2008.

Appel, B. R., Hoffer, E. M., Kothny, E. L., Wall, S. M., Haik, M., and Knights, R. L.: Analysis of carbonaceous material in Southern California atmospheric aerosols 2, Environ. Sci. Technol., 13, 98-104, 1979.

Arey, J., Atkinson, R., Zielinska, B., and McElroy, P. A.: Diurnal concentrations of volatile polycyclic aromatic hydrocarbons and nitroarenes during a photochemical air pollution episode in Glendora, California, Environ. Sci. Technol., 23, 321-327, 1989.

Brook, J. R., Graham, L., Charland, J. P., Cheng, Y., Fan, X., Lu, G., Li, S. M., Lillyman, C., MacDonald, P., Caravaggio, G., and MacPhee, J. A.: Investigation of the motor vehicle exhaust contribution to primary fine particle organic carbon in urban air, Atmos. Environ., 41, 119-135, 2007.

Caltrans. Traffic Operations Program, Traffic and Vehicle Data Systems website: http://www.interstate-guide.com/i-215_ca.html, 2007.

Canagaratna, M. R., Jayne, J. T., Jimenez, J. L., Allan, J. D., Alfarra, M. R., Zhang, Q., Onasch, T. B., Drewnick, F., Coe, H., Middlebrook, A., Delia, A., Williams, L. R., Trimborn, A. M., Northway, M. J., DeCarlo, P. F., Kolb, C. E., Davidovits, P., and Worsnop, D. R.: Chemical and microphysical characterization of ambient aerosols with the Aerodyne aerosol mass spectrometer, Mass Spectrom. Rev., 26, 185-222, 2007.

Chen, Q., Farmer, D. K., Schneider, J., Zorn, S. R., Heald, C. L., Karl, T. G., Guenther, A., Allan, J. D., Robinson, N., Coe, H., Kimmel, J. R., Pauliquevis, T., Borrmann, S., Pöschl, U., Andreae, M. O., Artaxo, P., Jimenez, J. L., and Martin, S. T.: Mass spectral characterization of submicron biogenic organic particles in the Amazon Basin, Geophys. Res. Lett., 36, L20806, doi:10.1029/2009GL039880, 2009.

Cubison, M. J., Ervens, B., Feingold, G., Docherty, K. S., Ulbrich, I. M., Shields, L., Prather, K., Hering, S., and Jimenez, J. L.: The influence of chemical composition and mixing state of Los Angeles urban aerosol on CCN number and cloud properties, Atmos. Chem. Phys., 8, 5649-5667, doi:10.5194/acp-8-5649-2008, 2008.

CARB. 2006 Area Designations for State Ambient Air Quality Standards, $\mathrm{PM}_{2.5}$, available at: http://www.arb.ca.gov/desig/ adm/2006/state_pm25.pdf, 2009.

DeCarlo, P. F., Kimmel, J. R., Trimborn, A., Northway, M. J., Jayne, J. T., Aiken, A. C., Gonin, M., Fuhrer, K., Horvath, T., Docherty, K., Worsnop, D. R., and Jimenez, J. L.: Fielddeployable, high-resolution, time-of-flight aerosol mass spectrometer, Anal. Chem., 78, 8281-8289, 2006.

DeCarlo, P. F., Dunlea, E. J., Kimmel, J. R., Aiken, A. C., Sueper, D., Crounse, J., Wennberg, P. O., Emmons, L., Shinozuka, Y., Clarke, A., Zhou, J., Tomlinson, J., Collins, D. R., Knapp, D., Weinheimer, A. J., Montzka, D. D., Campos, T., and Jimenez, J. L.: Fast airborne aerosol size and chemistry measurements above Mexico City and Central Mexico during the MILAGRO campaign, Atmos. Chem. Phys., 8, 4027-4048, doi:10.5194/acp8-4027-2008, 2008.
Denkenberger, K. A., Moffet, R. C., Holecek, J. C., Rebotier, T. P., and Prather, K. A.: Real-time, single-particle measurements of oligomers in aged ambient aerosol particles, Environ. Sci. Technol., 41, 5439-5446, 2007.

Docherty, K. S. and Jimenez, J. L.: Website and publication list for the Study of Organic Aerosols in Riverside (SOAR), available: http://cires.colorado.edu/jimenez-group/ Field/Riverside05/, 2009.

Docherty, K. S., Stone, E. A., Ulbrich, I. M., DeCarlo, P. F., Snyder, D. C., Schauer, J. J., Peltier, R. E., Weber, R. J., Murphy, S. M., Seinfeld, J. H., Eatough, D. J., and Jimenez, J. L.: Apportionment of primary and secondary organic aerosols in Southern California during the 2005 Study of Organic Aerosols in Riverside (SOAR-1), Environ. Sci. Technol., 42(20), 7655-7662, 2008.

Dockery, D. W., Pope III, C. A., Xu, X., Spengler, J. D., Ware, J. H., Fay, M. E., Ferris Jr., B. G., and Speizer, F. E.: An association between air pollution and mortality in six US cities, N. Engl. J. Med., 329, 1753-1759, 1993.

Donahue, N. M., Robinson, A. L., Stanier, C. O., and Pandis, S. N.: Coupled partitioning, dilution, and chemical aging of semivolatile organics, Environ. Sci. Technol. 40, 2635-2643, 2006.

Draxler, R. R. and Rolph, G. D.: HYSPLIT (HYbrid Single-Particle Lagrangian Integrated Trajectory) Model access via NOAA ARL READY Website: http://ready.arl.noaa.gov/HYSPLIT.php, NOAA Air Resources Laboratory, Silver Spring, MD, 2010.

Drewnick, F., Hings, S. S., Alfarra, M. R., Prévôt, A. S. H., and Borrmann, S.: Aerosol quantification with the Aerodyne Aerosol Mass Spectrometer: detection limits and ionizer background effects, Atmos. Meas. Tech., 2, 33-46, doi:10.5194/amt-2-332009, 2009.

Dunlea, E. J., DeCarlo, P. F., Aiken, A. C., Kimmel, J. R., Peltier, R. E., Weber, R. J., Tomlinson, J., Collins, D. R., Shinozuka, Y., McNaughton, C. S., Howell, S. G., Clarke, A. D., Emmons, L. K., Apel, E. C., Pfister, G. G., van Donkelaar, A., Martin, R. V., Millet, D. B., Heald, C. L., and Jimenez, J. L.: Evolution of Asian aerosols during transpacific transport in INTEX-B, Atmos. Chem. Phys., 9, 7257-7287, doi:10.5194/acp-9-7257-2009, 2009.

EPA, California $\mathrm{PM}_{2.5}$ designations map, available at: http://www. epa.gov/region9/air/maps/r9_pm25.html, 2009.

EPA MPBPWIN. v1.42, http://epa.gov/oppt/exposure/pubs/ episuite.htm, 2008.

EPA PMF User's Guide, 1.1, US Environmental Protection Agency: Washington, DC, 2005.

Falkovich, A. H. and Rudich, Y.: Analysis of semivolatile organic compounds in atmospheric aerosols by direct sample introduction thermal desorption GC/MS, Environ. Sci. Technol., 35, 2326-2333, 2001.

Fine, P. M., Cass, G. R., and Simoneit, B. R. T.: Chemical characterization of fine particle emissions from fireplace combustion of woods grown in the northeastern United States, Environ. Sci. Technol., 35, 2665-2675, 2001.

Fine, P. M., Chakrabarti, B., Krudysz, M., Schauer, J. J., and Sioutas, C.: Diurnal variations of individual organic compound constituents of ultrafine and accumulation mode particulate matter in the Los Angeles basin, Environ. Sci. Technol., 38, 12961304, 2004a.

Fine, P. M., Cass, G. R., and Simoneit, B. R. T.: Chemical 
characterization of fine particle emissions from wood stove combustion of prevalent United States tree species, Environ. Eng. Sci., 21(6), 705-721, 2004b.

Folinsbee, L. J.: Human health effects of air pollution, Environ. Health Persp., 100, 45-56, 1992.

Forstner, H. J. L., Flagan, R. C., and Seinfeld, J. H.: Molecular speciation of secondary organic aerosol from photooxidation of the higher alkenes: 1-octene and 1-decene, Atmos. Environ., 31(13), 1953-1964, 1997a.

Forstner, H. J. L., Flagan, R. C., and Seinfeld, J. H.: Secondary organic aerosol from the photooxidation of aromatic hydrocarbons: molecular composition, Environ. Sci. Technol., 31, 1345-1358, $1997 b$.

Fraser, M. P., Cass, G. R., and Simoneit, B. R. T.: Gas-phase and particle-phase organic compounds emitted from motor vehicle traffic in a Los Angeles roadway tunnel, Environ. Sci. Technol., 32, 2051-2060, 1998.

Gentner, D. R., Harley, R. A., Miller, A. M., and Goldstein, A. H.: Diurnal and seasonal variability of gasoline-related volatile organic compound emissions in Riverside, California, Environ. Sci. Technol., 43, 4247-4252, 2009.

Griffin, R. J., Chen, J., Carmody, K., Vutukuru, S., and Dabdub, D.: Contribution of gas phase oxidation of volatile organic compounds to atmospheric carbon monoxide levels in two areas of the United States, J. Geophys. Res., 112, D10S17, doi:10.1029/2006JD007602, 2007.

Harrison, M. A. J., Barra, S., Borghesi, D., Vione, D., Arsene, C., and Olariu, R. I.: Nitrated phenols in the atmosphere: a review, Atmos. Environ., 39, 231-248, 2005.

Herndon, S. C., Onasch, T. B., Wood, E. C., Kroll, J. H., Canagaratna, M. R., Jayne, J. T., Zavala, M. A., Knighton, W. B., Mazzoleni, C., Dubey, M. K., Ulbrich, I. M., Jimenez, J. L., Seila, R., de Gouw, J. A., de Foy, B., Fast, J., Molina, L. T., Kolb, C. E., and Worsnop, D. R.: Correlation of secondary organic aerosol with odd oxygen in Mexico City, Geophys. Res. Lett., 35, L15804, doi:10.1029/2008GL034058, 2008.

Hildemann, L. M., Markowski, G. R., and Cass, G. R.: Chemical composition of emissions from urban sources of fine organic aerosol, Environ. Sci. Technol., 25, 744-759, 1989.

Hodzic, A., Jimenez, J. L., Madronich, S., Aiken, A. C., Bessagnet, B., Curci, G., Fast, J., Lamarque, J.-F., Onasch, T. B., Roux, G., Schauer, J. J., Stone, E. A., and Ulbrich, I. M.: Modeling organic aerosols during MILAGRO: importance of biogenic secondary organic aerosols, Atmos. Chem. Phys., 9, 6949-6981, doi:10.5194/acp-9-6949-2009, 2009.

Intergovernmental Panel on Climate Change (IPCC) Climate Change 2007: The Physical Science Basis Contribution of Working Group I to the Fourth Assessment Report of the Intergovernmental Panel on Climate Change (Cambridge Univ. Press, Cambridge, UK), 2007.

Jaeckels, J. M., Bae, M. S., and Schauer, J. J.: Positive Matrix Factorization (PMF) analysis of molecular marker measurements to quantify the sources of organic aerosols, Environ. Sci. Technol., 41, 5763-5769, 2007.

Jang, M., Ghio, A. J., and Cao, G.: Exposure of BEAS-2B cells to secondary organic aerosol coated on magnetic nanoparticles, Chem. Res. Toxicol., 19(8), 1044-1050, doi:10.1021/tx0503597, 2006.

Jimenez, J. L., Canagaratna, M. R., Donahue, N. M., Prévôt, A. S.
H., Zhang, Q., Kroll, J. H., DeCarlo, P. F., Allan, J. D., Coe, H., Ng, N. L., Aiken, A. C., Docherty, K. S., Ulbrich, I. M., Grieshop, A. P., Robinson, A. L., Duplissy, J., Smith, J. D., Wilson, K. R., Lanz, V. A., Hueglin, C., Sun, Y. L., Tian, J., Laaksonen, A., Raatikainen, T., Rautiainen, J., Vaattovaara, P., Ehn, M., Kulmala, M., Tomlinson, J. M., Collins, D. R., Cubison, M. J., Dunlea, E. J., Huffman, J. A., Onasch, T. B., Alfarra, M. R., Williams, P. I., Bower, K., Kondo, Y., Schneider, J., Drewnick, F., Borrmann, S., Weimer, S., Demerjian, K., Salcedo, D., Cottrell, L., Griffin, R., Takami, A., Miyoshi, T., Hatakeyama, S., Shimono, A., Sun, J. Y., Zhang, Y. M., Dzepina, K., Kimmel, J. R., Sueper, D., Jayne, J. T., Herndon, S. C., Trimborn, A. M., Williams, L. R., Wood, E. C., Middlebrook, A. M., Kolb, C. E., Baltensperger, U., and Worsnop, D. R.: Evolution of organic aerosols in the atmosphere, Science, 326, 1525-1529, 2009.

Kanakidou, M., Seinfeld, J. H., Pandis, S. N., Barnes, I., Dentener, F. J., Facchini, M. C., Van Dingenen, R., Ervens, B., Nenes, A., Nielsen, C. J., Swietlicki, E., Putaud, J. P., Balkanski, Y., Fuzzi, S., Horth, J., Moortgat, G. K., Winterhalter, R., Myhre, C. E. L., Tsigaridis, K., Vignati, E., Stephanou, E. G., and Wilson, J.: Organic aerosol and global climate modelling: a review, Atmos. Chem. Phys., 5, 1053-1123, doi:10.5194/acp-5-1053-2005, 2005.

Ke, L., Liu, W., Wang, Y., Russell, A. G., Edgerton, E. S., and Zheng, M.: Comparison of $\mathrm{PM}_{2.5}$ source apportionment using positive matrix factorization and molecular marker-based chemical mass balance, Sci. Total Environ., 394(2-3), 290-302, 2008.

Kim, E., Hopke, P. K., and Edgerton, E. S.: Source identification of Atlanta aerosol by positive matrix factorization, J. Air Waste Manage., 53, 731-739, 2003.

Kleindienst, T. E., Jaoui, M., Lewandowski, M., Offenberg, J. H., Lewis, C. W., Bhave, P. V., and Edney, E. O.: Estimates of the contributions of biogenic and anthropogenic hydrocarbons to secondary organic aerosol at a southeastern US location, Atmos. Environ., 41, 8288-8300, 2007.

Kreisberg, N. M, Hering, S. V., Williams, B. J., Worton, D. R., and Goldstein, A. H.: Quantitation of hourly speciated organic compounds in atmospheric aerosols, Measured by in-situ thermal desorption aerosol gas chromatography (TAG), Aerosol Sci. Technol., 43(1), 38-52, 2009.

Lambe, A. T., Logue, J. M., Kreisberg, N. M., Hering, S. V., Worton, D. R., Goldstein, A. H., Donahue, N. M., and Robinson, A. L.: Apportioning black carbon to sources using highly timeresolved ambient measurements of organic molecular markers in Pittsburgh, Atmos. Environ., 43, 3941-3950, 2009a.

Lambe, A. T., Miracolo, M. M., Hennigan, C. J., Robinson, A. L., and Donahue, N. M.: Effective rate constants and uptake coefficients for the reactions of organic molecular markers (nalkanes, hopanes and steranes) in motor oil and diesel primary organic aerosols with hydroxyl radicals, Environ. Sci. Technol., 43, 8794-8800, 2009b.

Lanz, V. A., Alfarra, M. R., Baltensperger, U., Buchmann, B., Hueglin, C., and Prévôt, A. S. H.: Source apportionment of submicron organic aerosols at an urban site by factor analytical modelling of aerosol mass spectra, Atmos. Chem. Phys., 7, 1503-1522, doi:10.5194/acp-7-1503-2007, 2007.

Lanz, V. A., Alfarra, M. R., Baltensperger, U., Buchmann, B., Hueglin, C., Szidat, S., Wehrli, M. N., Wacker, L., Weimer, S., Caseiro, A., Puxbaum, H., and Prévôt, A. S. H.: Source 
attribution of submicron organic aerosols during wintertime inversions by advanced factor analysis of aerosol mass spectra, Environ. Sci. Technol., 42, 214-220, 2008.

Lough, G. C., Schauer, J. J., and Lawson, D. R.: Day-of-week trends in carbonaceous aerosol composition in the urban atmosphere, Atmos. Environ., 40, 4137-4149, 2006.

Matsunaga, S. N., Guenther, A. B., Potosnak, M. J., and Apel, E. C.: Emission of sunscreen salicylic esters from desert vegetation and their contribution to aerosol formation, Atmos. Chem. Phys., 8, 7367-7371, doi:10.5194/acp-8-7367-2008, 2008.

Maykut, N. N., Lewtas, J., Kim, E., and Larson, T. V.: Source apportionment of $\mathrm{PM}_{2.5}$ at an urban IMPROVE site in Seattle, Washington, Environ. Sci. Technol., 37, 5135-5142, doi:10.1021/es030370y, 2003.

Millet, D. B., Donahue, N. M., Pandis, S. N., Polidori, A., Stanier, C. O., Turpin, B. J., and Goldstein, A. H.: Atmospheric VOC measurements during the Pittsburgh Air Quality Study: Results, interpretation and quantification of primary and secondary contributions, J. Geophys. Res., 110, D07S07, doi:10.1029/2004JD004601, 2005.

Millet, D. B., Goldstein, A. H., Holzinger, R., Williams, B. J., Allan, J. D., Jimenez, J. L., Worsnop, D. R., Roberts, J. M., White, A. B., Hudman, R. C., Bertschi, I. T., and Stohl, A.: Chemical characteristics of North American surface-layer outflow: Insights from Chebogue Point, J. Geophys. Res., 111, D23S53, doi:10.1029/2006JD007287, 2006.

Mohr, C., Huffman, J. A., Cubison, M. J., Aiken, A. C., Docherty, K. S., Kimmel, J. R., Ulbrich, I. M., Hannigan, M., and Jimenez, J. L.: Characterization of primary organic aerosol emissions from meat cooking, trash burning, and motor vehicles with highresolution aerosol mass spectrometry and comparison with ambient and chamber observations, Environ. Sci. Technol., 43, 2443 2449, 2009.

Murphy, D. M., Cziczo, D. J., Froyd, K. D., Hudson, P. K., Matthew, B. M., Middlebrook, A. M., Peltier, R. E., Sullivan, A., Thomson, D. S., and Weber, R. J.: Single-particle mass spectrometry of tropospheric aerosol particles, J. Geophys. Res.-Atmos., 111, D23S32, doi:10.1029/2006JD007340, 2006.

Lanz, V. A., Alfarra, M. R., Baltensperger, U., Buchmann, B., Hueglin, C., and Prévôt, A. S. H.: Source apportionment of submicron organic aerosols at an urban site by factor analytical modelling of aerosol mass spectra, Atmos. Chem. Phys., 7, 1503-1522, doi:10.5194/acp-7-1503-2007, 2007.

Noble, C. A. and Prather, K. A.: Real time measurement of correlated size and composition profiles of individual atmospheric aerosol particles, Environ. Sci. Technol., 30, 2667-2680, 1996.

Paatero, P.: Least squares formulation of robust non-negative factor analysis, chemometrics and intelligent laboratory systems, Chemometr. Intell. Lab., 37, 23-35, 1997.

Pandis, S. N., Harley, R. A., Cass, G. R., and Seinfeld, J. H.: Secondary organic aerosol formation and transport, Atmos. Environ. A, 26, 2269-2282, 1992.

Parker P. A. and Chen, G.: Internal estimate of random uncertainties, First International Tropospheric Airborne Measurement Evaluation Panel (TAbMEP) Meeting, available at: http://www-air.larc.nasa.gov/Measures/Presentations/ UncertaintyEstimates081908_PARKER.pdf, 2008.

Phuleria, H. C., Fine, P. M., Zhu, Y., and Sioutas, C.: Air quality impacts of the October 2003 southern California wildfires, J. Geo- phys. Res.-Atmos., 110, D07S20, doi:10.1029/2004JD004626, 2005.

Pope III, C. A., Ezzati, M., and Dockery, D. W.: Fine-particulate air pollution and life expectancy in the United States, N. Engl. J. Med., 360, 376-386, 2009.

Ramanathan, V., Crutzen, P. J., Kiehl, J. T., and Rosenfeld, D.: Atmosphere-Aerosols, climate, and the hydrological cycle, Science, 294(5549), 2119-2124, 2001.

Reynolds, J. C., Last, D. J., McGillen, M., Nijs, A., Horn, A. B., Percival, C., Carpenter, L. J., and Lewis, A. C.: Structural analysis of oligimeric molecules formed from the reaction products of oleic acid ozonolysis, Environ. Sci. Technol., 40(21), 66746681, 2006.

Robinson, A. L., Subramanian, R., Donahue, N. M., BernardoBricker, A., and Rogge, W. F.: Source apportionment of molecular markers and organic aerosol. 3. Food cooking emissions, Environ. Sci. Technol., 40, 7820-7827, 2006.

Rogge, W. F., Hildemann, L. M., Mazurek, M. A., Cass, G. R., and Simoneit, B. R. T.: Sources of fine organic aerosol: 1. Charbroilers and meat cooking operations, Environ. Sci. Technol., 25, 1112-1125, 1991.

Rogge, W. F., Hildemann, L. M., Mazurek, M. A., Cass, G. R., and Simoneit, B. R. T.: Sources of fine organic aerosol: 2. Noncatalyst and catalyst-equipped automobiles and heavy-duty diesel trucks, Environ. Sci. Technol., 27, 636-651, 1993.

Rogge, W. F., Hildemann, L. M., Mazurek, M. A., and Cass, G. R.: Sources of fine organic aerosol 9: pine oak and synthetic log combustion in residential fireplaces, Environ. Sci. Techol., 32, 13-22, 1998.

Rolph, G. D.: Real-time Environmental Applications and Display sYstem (READY) Website: http://ready.arl.noaa.gov, NOAA Air Resources Laboratory, Silver Spring, MD, 2010.

Rudich, Y., Donahue, N. M., and Mentel, T. F.: Aging of organic aerosol: Bridging the gap between laboratory and field studies, Annu. Rev. Phys. Chem., 58, 321-352, 2007.

Sawant, A. A., Na, K., Zhu, X., and Cocker III, D. R.: Chemical characterization of outdoor $\mathrm{PM}_{2.5}$ and gas-phase compounds in Mira Loma, California, Atmos. Environ., 38, 5517-5528, 2004.

Schauer J. J., Kleeman, M. J., Cass, G. R., and Simoneit, B. R. T.: Measurement of emissions from air pollution sources. 2. $\mathrm{C}_{1}$ through $\mathrm{C}_{30}$ organic compounds from medium duty diesel trucks, Environ. Sci. Technol., 33, 1578-1587, 1999.

Schauer J. J., Kleeman, M. J., Cass, G. R., and Simoneit, B. R. T.: Measurement of emissions from air pollution sources. 5. $\mathrm{C}_{1}$ through $\mathrm{C}_{32}$ organic compounds from gasoline-powered motor vehicles, Environ. Sci. Technol., 36, 1169-1180, 2002.

Schwartz, J., Dockery, D. W., and Neas, L. M.: Is daily mortality associated specifically with fine particles?, J. Air Waste Manage. Assoc., 46, 927-939, 1996.

Schwartz, J., Ballester, F., Saez, M., Perez-Hoyos, S., Bellido, J., Cambra, K., Arribas, F., Canada, A., Perez-Boillos, M. J., and Sunyer, J.: The concentration - response relation between air pollution and daily deaths, Environ. Health Perspect., 109(10), 1001-1006, 2001.

Shields, L. G., Qin, X., Toner, S. M., and Prather, K. A.: Detection of Ambient Ultrafine Aerosols by Single Particle Techniques During the SOAR 2005 Campaign, Aerosol Sci. Technol., 42(8), 674-684, 2008.

Shrivastava, M. K., Subramanian, R., Rogge, W. F., and Robinson, 
A. L.: Sources of organic aerosol: positive matrix factorization of molecular marker data and comparison of results from different source apportionment models, Atmos. Environ., 41(40), 93539369, 2007.

Simoneit B. R. T.: Organic matter of the troposphere-III. Characterization and sources of petroleum and pyrogenic residues in aerosols over the western United States, Atmos. Environ., 18, 51-67, 1984.

Simoneit, B. R. T.: Organic matter of the troposphere-V. Application of molecular marker analysis to biogenic emissions into the troposphere for source reconciliations, J. Atmos. Chem. 8, 251$275,1989$.

Simoneit, B. R. T., Rogge, W. F., Mazurek, M. A., Standley, L. J., Hildemann, L. M., and Cass, G. R.: Lignin pyrolysis products, lignans, and resin acids as specific tracers of plant classes in emissions from biomass combustion, Environ. Sci. Technol., 27, 2533-2541, 1993.

Singh, H. B., Salas, L., Kolyer, R., Czech, E., Viezee, W., Li, Q., Jacob, D. J., Blake, D., Sachse, G., Harward, C. N., Fuelberg, H., Kiley, C. M., Zhao, Y., and Kondo, Y.: In situ measurements of $\mathrm{HCN}$ and $\mathrm{CH} 3 \mathrm{CN}$ over the Pacific Ocean: Sources, sinks, and budgets, J. Geophys. Res., 108(D20), 8795, doi:10.1029/2002JD003006, 2003.

Smith, J. N., Barsanti, K. C., Friedli, H. R., Ehn, M., Kulmala, M., Collins, D. R., Scheckman, J. H., Williams, B. J., and McMurry, P. H.: Observations of aminium salts in atmospheric nanoparticles and possible climatic implications, P. Natl, Acad. Sci., 107, 6634-6639, doi:10.1073/pnas.0912127107, 2010.

Snyder, D. C. and Schauer, J. J.: An inter-comparison of two black carbon aerosol instruments and a semi-continuous elemental carbon instrument in the urban environment, Aerosol Sci. Technol., 41(5), 463-474, 2007.

Stout, S. A. and Douglas, G. S.: Diamondoid hydrocarbons - Application in the chemical fingerprinting of natural gas condensate and gasoline, Environmental Forensics, 5, 225-235, 2004.

Tobias, H. J., Docherty, K. S., Beving, D. E., and Ziemann, P. J.: Effect of relative humidity on the chemical composition of secondary organic aerosol formed from reactions of 1-tetradecene and $\mathrm{O}_{3}$, Environ. Sci. Technol., 34, 2116-2125, 2000.

Turpin, B. J. and Huntzicker, J. J.: Identification of secondary organic aerosol episodes and quantitation of primary and secondary organic aerosol concentrations during SCAQS, Atmos. Environ., 29, 3527-3544, 1995.

Ulbrich, I. M., Canagaratna, M. R., Zhang, Q., Worsnop, D. R., and Jimenez, J. L.: Interpretation of organic components from Positive Matrix Factorization of aerosol mass spectrometric data, Atmos. Chem. Phys., 9, 2891-2918, doi:10.5194/acp-9-2891-2009, 2009.

US Census Bureau: State and County Quickfacts Website: http: //quickfacts.census.gov/qfd/states/06000.html, 2008.

Wang, L., Arey, J., and Atkinson, R.: Kinetics and products of photolysis and reaction with $\mathrm{OH}$ radicals of a series of aromatic carbonyl compounds, Environ. Sci. Technol., 40, 5465-5471, 2006.

Wang, L., Atkinson, R., and Arey, J.: Dicarbonyl products of the $\mathrm{OH}$ radical-initiated reactions of naphthalene and the $\mathrm{C} 1$ - and C2-alkylnaphthalenes, Environ. Sci. Technol., 41, 2803-2810, 2007.
Weitkamp, E. A., Huff Hartz, K. E., Sage, A. M., Donahue, N. M., and Robinson, A. L.: Laboratory measurements of the heterogeneous oxidation of condensed-phase organic molecular makers for meat cooking emissions, Environ. Sci. Technol., 42, 51775182, 2008a.

Weitkamp, E. A., Lambe, A. T., Donahue, N. M., and Robinson, A. L.: Laboratory measurements of the heterogeneous oxidation of condensed-phase organic molecular makers for motor vehicle exhaust, Environ. Sci. Technol., 42, 7950-7956, doi:10.1021/es800745x, 2008b.

Williams, B. J., Goldstein, A. H., Kreisberg, N. M., and Hering, S. V.: An in-situ instrument for speciated organic composition of atmospheric aerosols: Thermal desorption aerosol GC/MS-FID (TAG), Aerosol Sci. Technol., 40, 627-638, 2006.

Williams, B. J., Goldstein, A. H., Millet, D. B., Holzinger, R., Kreisberg, N. M., Hering, S. V., White, A. B., Worsnop, D. R., Allan, J. D., and Jimenez, J. L.: Chemical speciation of organic aerosol during the International Consortium for Atmospheric Research on Transport and Transformation 2004: Results from in situ measurements, J. Geophys. Res., 112, D10S26, doi:10.1029/2006JD007601, 2007.

Williams, B. J., Goldstein, A. H., Kreisberg, N. M., and Hering, S. V.: In-situ measurements of gas/particle phase transitions for atmospheric semivolatile organic compounds, P. Natl. Acad. Sci USA, 107, 6676-6681, doi:10.1073/pnas.0911858107, 2010.

Xie, Y. L., Hopke, P. K., Paatero, P., Barrie, L. A., and Li, S. M.: Identification of source nature and seasonal variations of arctic aerosol by positive matrix factorization, J. Atmos. Sci., 56, 249260, 1999.

Zhang, Q., Worsnop, D. R., Canagaratna, M. R., and Jimenez, J. L.: Hydrocarbon-like and oxygenated organic aerosols in Pittsburgh: insights into sources and processes of organic aerosols, Atmos. Chem. Phys., 5, 3289-3311, doi:10.5194/acp-5-32892005, 2005.

Zhang, Q., Jimenez, J. L., Canagaratna, M. R., Allan, J. D., Coe, H., Ulbrich, I., Alfarra, M. R., Takami, A., Middlebrook, A. M., Sun, Y. L., Dzepina, K., Dunlea, E., Docherty, K., DeCarlo, P. F., Salcedo, D., Onasch, T., Jayne, J. T., Miyoshi, T., Shimono, A., Hatakeyama, S., Takegawa, N., Kondo, Y., Schneider, J., Drewnick, F., Borrmann, S., Weimer, S., Demerjian, K., Williams, P., Bower, K., Bahreini, R., Cottrell, L., Griffin, R. J., Rautiainen, J., Sun, J. Y., Zhang, Y. M., and Worsnop, D. R.: Ubiquity and dominance of oxygenated species in organic aerosols in anthropogenically-influenced northern hemisphere mid-latitudes, Geophys. Res. Lett., 34, L13801, doi:10.1029/2007GL029979, 2007.

Zhao, Y., Hu, M., Slanina, S., and Zhang, Y.: The molecular distribution of fine particulate organic matter emitted from westernstyle fast food cooking, Atmos. Environ., 41(37), 8163-8171, 2007.

Zheng, M., Cass, G. R., Schauer, J. J., and Edgerton, E. S.: Source apportionment of $\mathrm{PM}_{2.5}$ in the southern United States using solvent-extractable organic compounds as tracers, Environ. Sci. Technol., 36, 2361-2371, 2002. 